\title{
Blended Self-Management Interventions to Reduce Disease Burden in Patients With Chronic Obstructive Pulmonary Disease and Asthma: Systematic Review and Meta-analysis
}

Xiaoyue Song ${ }^{1}$, MSc; Cynthia Hallensleben ${ }^{1}$, BSc; Weihong Zhang ${ }^{2}, \mathrm{PhD}$; Zongliang Jiang ${ }^{2}$, BSc; Hongxia Shen ${ }^{1}$, MSc; Robbert J J Gobbens ${ }^{3,4,5}$, PhD; Rianne M J J Van Der Kleij ${ }^{1}, \mathrm{PhD}$; Niels H Chavannes ${ }^{1}, \mathrm{MD}, \mathrm{PhD}$; Anke Versluis ${ }^{1}, \mathrm{PhD}$

\footnotetext{
${ }^{1}$ Department of Public Health and Primary Care, Leiden University Medical Center, Leiden, Netherlands

${ }^{2}$ Faculty of Nursing and Health, Zhengzhou University, Zhengzhou, China

${ }^{3}$ Faculty of Health, Sports and Social Work, Inholland University of Applied Sciences, Amsterdam, Netherlands

${ }^{4}$ Zonnehuisgroep Amstelland, Amstelveen, Netherlands

${ }^{5}$ Department Family Medicine and Population Health, Faculty of Medicine and Health Sciences, University of Antwerp, Antwerp, Belgium
}

Corresponding Author:

Xiaoyue Song, MSc

Department of Public Health and Primary Care

Leiden University Medical Center

Albinusdreef 2

Leiden, 2333 ZA

Netherlands

Phone: 31613836216

Email: x.song@lumc.nl

\section{Abstract}

Background: Chronic obstructive pulmonary disease (COPD) and asthma have a high prevalence and disease burden. Blended self-management interventions, which combine eHealth with face-to-face interventions, can help reduce the disease burden.

Objective: This systematic review and meta-analysis aims to examine the effectiveness of blended self-management interventions on health-related effectiveness and process outcomes for people with COPD or asthma.

Methods: PubMed, Web of Science, COCHRANE Library, Emcare, and Embase were searched in December 2018 and updated in November 2020. Study quality was assessed using the Cochrane risk of bias (ROB) 2 tool and the Grading of Recommendations, Assessment, Development, and Evaluation.

Results: A total of 15 COPD and 7 asthma randomized controlled trials were included in this study. The meta-analysis of COPD studies found that the blended intervention showed a small improvement in exercise capacity (standardized mean difference [SMD] 0.48; 95\% CI 0.10-0.85) and a significant improvement in the quality of life (QoL; SMD 0.81; 95\% CI 0.11-1.51). Blended intervention also reduced the admission rate (relative ratio [RR] $0.61 ; 95 \%$ CI $0.38-0.97$ ). In the COPD systematic review, regarding the exacerbation frequency, both studies found that the intervention reduced exacerbation frequency (RR 0.38 ; $95 \%$ CI 0.26-0.56). A large effect was found on BMI ( $d=0.81$; 95\% CI $0.25-1.34)$; however, the effect was inconclusive because only 1 study was included. Regarding medication adherence, 2 of 3 studies found a moderate effect $(d=0.73$; 95\% CI 0.50-0.96), and 1 study reported a mixed effect. Regarding self-management ability, 1 study reported a large effect $(d=1.15$; 95\% CI 0.66-1.62), and no effect was reported in that study. No effect was found on other process outcomes. The meta-analysis of asthma studies found that blended intervention had a small improvement in lung function (SMD 0.40; 95\% CI 0.18-0.62) and QoL (SMD 0.36; 95\% CI 0.21-0.50) and a moderate improvement in asthma control (SMD 0.67; 95\% CI 0.40-0.93). A large effect was found on BMI $(d=1.42 ; 95 \%$ CI $0.28-2.42)$ and exercise capacity $(d=1.50 ; 95 \%$ CI $0.35-2.50)$; however, 1 study was included per outcome. There was no effect on other outcomes. Furthermore, the majority of the 22 studies showed some concerns about the ROB, and the quality of evidence varied.

Conclusions: In patients with COPD, the blended self-management interventions had mixed effects on health-related outcomes, with the strongest evidence found for exercise capacity, QoL, and admission rate. Furthermore, the review suggested that the interventions resulted in small effects on lung function and QoL and a moderate effect on asthma control in patients with asthma. 
There is some evidence for the effectiveness of blended self-management interventions for patients with COPD and asthma; however, more research is needed.

Trial Registration: PROSPERO International Prospective Register of Systematic Reviews CRD42019119894; https://www.crd.york.ac.uk/prospero/display_record.php?RecordID=119894

(J Med Internet Res 2021;23(3):e24602) doi: 10.2196/24602

\section{KEYWORDS}

blended intervention; COPD; asthma; meta-analysis; systematic review

\section{Introduction}

\section{Background}

Chronic lung diseases are the leading cause of disability and death worldwide [1]. Of all chronic lung diseases, chronic obstructive pulmonary disease (COPD) and asthma are the most prevalent [1]. There were approximately 251 million cases of COPD globally in 2015, and COPD is predicted to become the third leading cause of death by 2030 [2]. Approximately 300 million people have asthma worldwide, with a projected increase of an additional 100 million people by 2025 [3]. The impact of a health problem, measured by financial cost, morbidity, and other indicators, is called disease burden. It is often quantified in terms of disability-adjusted life years (DALYs) or quality-adjusted life years (QALYs) [1]. In 2017, the loss of DALYs was the first for COPD and the second for asthma [1]. In addition, a loss in health-related quality of life (QoL) is seen in many patients (eg, a decline in health, increased hospital admissions, and high medication costs). The World Health Organization estimates that the cost of a QALY for COPD ranges from US $\$ 6700$ to $\$ 13,400$ due to exacerbations and medication. In patients with asthma, annual costs vary from less than US $\$ 150$ to US $\$ 3000$ [4,5]. There is increased awareness that self-management represents a promising strategy to decrease disease burden [6]. Self-management could improve patient outcomes and decrease disease burden by supporting patients to positively adapt their health behaviors and develop skills to better manage their diseases [7].

Self-management refers to an individual's ability to manage their symptoms, treatment, physical and psychosocial consequences, and lifestyle changes inherent to life with a chronic condition [8]. In traditional face-to-face self-management interventions, patients with COPD and asthma are equipped with the knowledge and skills to manage their health condition successfully [9]. Previous studies have found that these self-management interventions are effective in improving disease knowledge and self-efficacy [10]. However, these face-to-face self-management interventions are limited by their accessibility (eg, lower accessibility for patients who are more distant to the health care provider or when the health care provider lacks time) [11].

eHealth is an alternative to traditional face-to-face interventions. The most cited definition of eHealth is "health services and information delivered or enhanced through the internet and related technologies" [12]. Compared with traditional face-to-face interventions, eHealth interventions can be cost and time saving and offer better accessibility and flexibility
[13]. Moreover, eHealth interventions can help optimize the therapeutic process, increase treatment efficiency, and decrease costs by enhancing (web-based) communication possibilities between health care providers and patients [14]. There have been promising results with eHealth self-management interventions $[15,16]$. A meta-analysis showed that, for patients with COPD, eHealth self-management programs (eg, web-based phone calls and web-based interventions) led to a significant improvement in symptoms [15]. However, eHealth interventions typically allow for limited tailoring of patients' needs and lower patient engagement [17]. There have also been concerns about reliability, security, confidentiality, and lack of education and training [18]. These factors can negatively impact the implementation and effectiveness of these interventions.

The most recent development is the blended intervention. There are different definitions of blended interventions [19,20]. We use the definition by Erbe et al [20]: "Treatment programs that use elements of both face-to-face and internet-based interventions, including both the integrated and the sequential use of both treatment formats." Blended interventions could retain the positive aspects of face-to-face interventions and eHealth by mitigating their negative aspects. Furthermore, blended intervention could diminish the number of face-to-face contacts needed and provide support that is available at all times [21]. With eHealth, patients can also monitor their health condition throughout the day and convey their health information to health care providers without time and distance limitations. Patients can also receive quick assistance during critical periods of care facilitated by real-time alerts and reminders, which could help patients adhere to their action plan. For patients with COPD and asthma, blended interventions can include various elements [22,23] (eg, training, education, and action plans) with different blended intervention components (eg, internet-based phone calls and individual face-to-face interventions, web platforms combined with individual face-to-face interventions) [22,23]. Some studies have shown that blended self-management interventions are effective in improving QoL in patients with COPD and asthma [24,25].

Current reviews suggest that blended interventions could be effective [19,20], but these reviews are limited for several reasons. First, the reviews focus on mental health and not on chronic lung diseases [20]. Second, the reviews focus on health-related effectiveness outcomes and not on process outcomes [19]. Third, the reviews do not specifically focus on self-management interventions [19,20]. To conclude, a comprehensive overview or meta-analysis of the effect of blended self-management interventions on the disease burden 
of patients with COPD and asthma, including process outcomes and health-related effectiveness outcomes, is lacking.

\section{Objectives}

A systematic review will be performed to assess the effectiveness of blended self-management interventions in patients with COPD and asthma. When appropriate, a meta-analysis will be conducted. Internet-based, telephone, and SMS-delivered interventions are included because all of these are parts of eHealth [13]. Thus, this study aims to investigate the effectiveness of blended self-management interventions in patients with COPD and asthma.

\section{Methods}

\section{Systematic Review and Meta-analysis}

This review follows the PRISMA (Preferred Reporting Items for Systematic Reviews and Meta-Analyses) guidelines [26]. The review was registered in PROSPERO (number 2019: CRD42019119894).

\section{Search Strategy}

A search strategy was established in collaboration with a certified librarian to identify relevant studies on blended self-management interventions in patients with COPD and asthma. A total of 5 electronic databases (ie, PubMed, Web of Science, COCHRANE Library, Emcare, and Embase) were searched on December 28, 2018, and updated on November 30, 2020. There were search terms related to 4 areas: (1) COPD or asthma, (2) eHealth, (3) face-to-face intervention, and (4) blended intervention (Multimedia Appendix 1). The search terms related to COPD or asthma and blended interventions were first combined, resulting in 84 studies. Due to the limited number of studies, the search terms associated with COPD or asthma were combined with terms about eHealth and face-to-face interventions. In every database, the search was limited to peer-reviewed publications. The search strategy was not restricted based on publication year, as we aimed to provide a comprehensive overview of the use of blended interventions in patients with COPD and asthma. In addition, reference lists of the included studies and previous reviews were searched to identify additional studies that might be eligible for inclusion.

\section{Eligibility Criteria}

The patient, intervention, comparison, outcome, study design tool was used to develop an effective search strategy and determine the inclusion and exclusion criteria [27]. The following inclusion criteria were used to identify the studies: (1) participants: adults ( $\geq 18$ years old) with COPD or asthma; (2) intervention: blended self-management intervention (consisting of an eHealth component combined with a face-to-face component); (3) comparison: eHealth intervention with or without usual care (UC) and face-to-face intervention with or without UC or only UC; (4) outcome measures: health-related effectiveness or process outcomes; and (5) individual randomized controlled trials (RCTs). Studies were excluded if: (1) the participants were children or adolescents, (2) the eHealth apps were only used to collect data, (3) outcomes

were not about the health-related outcomes, and (4) studies were cluster RCTs.

\section{Study Selection}

After the removal of duplicates, the identified titles and abstracts were screened for eligibility. If insufficient information was provided, the full-text paper was screened. When a full-text paper was not available, a request was sent to the authors. Studies that did not meet the inclusion criteria were excluded. Screening the titles, abstracts, and full texts was performed by 2 reviewers independently (XS and ZJ). Any disagreements between the 2 authors were resolved by a third reviewer $(\mathrm{CH})$.

\section{Data Collection and Coding}

Data were collected using a standardized data extraction form. It included (1) study characteristics (eg, first author, publication year, country, number and age of patients, percentage of female patients, disease severity or diagnosis, setting [ie, home, primary care (PC), or secondary care (SC)]), intervention, and follow-up duration), (2) intervention characteristics (ie, category and functionality of the eHealth and face-to-face component), (3) behavior change techniques (BCTs) used in the blended self-management intervention, and (4) the health-related effectiveness and process outcomes. Information was extracted from each publication by XS and ZJ. Inter-rater reliability, as assessed with Cohen $\kappa$, indicated strong agreement $(\kappa=0.90)$ [28].

COPD severity was classified based on the Global Initiative for Chronic Obstructive Lung Disease (GOLD) criteria [29]. Patients were considered to have COPD when the ratio between forced expiratory volume in 1s (FEV1) and full forced vital capacity (FVC) was $<0.70$. The degree of obstruction was defined as follows: (1) GOLD I: FEV1 $\geq 80 \%$ predicted (mild), (2) GOLD II: $50 \% \leq \mathrm{FEV} 1<80 \%$ predicted (moderate), (3) GOLD III: $30 \% \leq \mathrm{FEV} 1<50 \%$ predicted (severe), and (4) GOLD IV: FEV1 $<30 \%$ predicted (very severe). There is no standard classification of severity for patients with asthma.

As mentioned above, different intervention characteristics were extracted from the publications. First, the eHealth component of the intervention was categorized as a mobile app; eg, phone call or SMS), an internet-assisted intervention (eg, web page, chat room), or multiple component interventions with multiple eHealth technologies. Second, the function of the eHealth app was categorized into informing, instructing, displaying, guiding, reminding or alerts, and communicating (ie, between provider and patients) [30]. Third, face-to-face interventions were classified as individual (eg, home visits, PC or SC visits) or group-based interventions (eg, group pulmonary rehabilitation). Fourth, the function of the face-to-face intervention was classified as (1) education: introduction of disease-related information and how to use eHealth, (2) training: provide information about self-management, (3) consultation: discuss individual action plan, (4) assessment: test and assess the patient's performance, or (5) monitoring: provide reminders to improve intervention adherence [31,32].

Outcome indicators were classified into health-related effectiveness outcome or process outcome indicators. Health-related effectiveness outcome indicators included 
outcomes related to disease status and health condition (ie, exercise capacity, dyspnea, lung function, QoL, admission, mortality, exacerbation frequency, and BMI). Process outcome indicators included intermediate outcomes during the implementation process (eg, visits, satisfaction, costs, smoking, self-management ability, physical activity, medication and therapy adherence, psychosocial, symptom management, nutrition, and alcohol). A positive effect was ascribed when there was a significant positive effect of the intervention on the outcome measure compared with the control group (CG). When the outcome measure did not significantly differ between the intervention group (IG) and CG, it was rated as no effect. A mixed effect was ascribed when multiple measures were used to measure a similar outcome, and the effect on the measures was in different directions (eg, in the study by Garcia [22], there was a significant positive effect on inhaler treatment adherence, whereas there was no effect on oral treatment adherence).

\section{Quality Assessment}

Study quality was assessed using the Cochrane risk of bias (ROB) 2 tool [33]. The tool assessed 5 domains of potential bias: (1) randomization, (2) deviations from the intended interventions (effect of assignment to intervention), (3) missing outcome data, (4) measurement of the outcome, and (5) selection of the reported result. Each domain had a few signaling questions. On the basis of the authors' (XS and ZJ) responses to the signaling questions, a judgment on the ROB (low, some concerns, or high) for each domain could be made to assess the bias that might confound the study findings [33]. The quality of the clinical evidence was critically appraised using the Grading of Recommendations, Assessment, Development, and Evaluation (GRADE) system [34], which evaluated the risk for bias, inconsistency, indirectness, and imprecision for each outcome. Four categories were used to define the quality of evidence: high quality of evidence (the true effect lies close to that of the effect estimate), moderate quality of evidence (the true effect is likely to be close to the effect estimate, but there is a possibility that it is substantially different), low quality of evidence (the true effect may be substantially different from the effect estimate), and very low quality of evidence (the true effect is likely to be substantially different from the effect estimate) [35]. The quality assessment was performed by XS and ZJ, and any disagreements were resolved through discussion. Inter-rater reliability, as assessed with Cohen $\kappa$ [28], indicated that there was strong agreement between raters $(\kappa=0.80)$.

\section{Data Analysis}

When an outcome was assessed using different measurements in one study, data from the most specific disease-related questionnaire were used. For example, in the study by Garcia [22], QoL was measured using both the Saint-George's Respiratory Questionnaire (SGRQ), a specific QoL questionnaire, and Euroqol, a generic health-related QoL questionnaire. SGRQ was selected and analyzed in the meta-analysis because it is the most specific disease-related questionnaire.

First, a systematic review was conducted to determine the results. For continuous data, Cohen $d$ was recommended to calculate the effect size [36] (Cohen $d>0.2=$ small effect, Cohen $d>0.5=$ moderate effect, and Cohen $d>0.8=$ large effect) [37]. For dichotomous data, the relative ratio (RR) was calculated to assess the effect size. An RR greater than 1 indicates an increased likelihood that the stated outcome is achieved in the IG. If the RR is less than 1, there is a decreased likelihood that the outcome is achieved in the IG. A ratio of 1 indicated no difference (ie, the outcome was just as likely to occur in the IG as it was in the CG) [38].

When 3 or more studies reported on the same outcome measure, this outcome was included in the meta-analysis [39]. For continuous data, the standardized mean difference (SMD) accounted for the same outcomes measured with different assessment tools (eg, QoL was assessed using the SGRQ, COPD assessment test [CAT], and chronic respiratory questionnaire [CRQ]). SMDs were used to standardize the results of the studies to a uniform scale before they could be combined in the quantitative synthesis. SMDs and associated 95\% CIs were used to calculate the mean difference and SD difference between the IG and CG for each study. When the mean or SD was not mentioned, the author was contacted for missing information. Cohen $d$ was used to interpret the data [37]. For dichotomous data, RR was calculated to assess the effect size [38]. Publication bias was tested if more than 10 studies report on the same outcome measure [40]. $P<.05$ was considered significant for the effect estimate.

A random-effect model was used because the variance of study populations and intervention designs was anticipated as heterogeneity across the included studies [41]. Heterogeneity was assessed using chi-square tests and $I^{2}$ statistics [42]. A $P$ value of $<.1$ indicates statistically significant heterogeneity. The $I^{2}$ statistic was used to quantify the size of the heterogeneity between studies: $25 \%, 50 \%$, and $75 \%$ can be considered small, medium, and substantial heterogeneity, respectively [42]. Outliers were identified using the value of the standardized residual [43]. Studies whose standardized residual was equal to or larger than 1.96 were identified as an outlier and were excluded from the meta-analysis. No subgroup analysis was planned because of the limited number of studies. All analyses were performed using the Review Manager (RevMan version 5.4; The Cochrane Collaboration) and Stata version 14.0 (StataCorp) [44].

\section{Results}

\section{Search Results}

The literature search identified a total of 4495 potentially eligible records, and 2657 records remained after duplicates were excluded. After screening the titles and abstracts, additional 2531 records were excluded for other reasons (Figure 1). The full texts of the remaining 126 studies were assessed, and 22 RCTs [22-25,45-62] were included in this review. Of the 22 RCTs, 2 were pilot RCT studies [45,51] and 1 was a feasibility RCT [48]. These studies were included because they followed the CONSORT (Consolidated Standards of Reporting Trials) checklist [45,51], and they were small sample size RCTs [48,51]. A total of 15 RCTs focused on patients with COPD $[22,24,45-57]$. Of these studies, 11 were included in the 
meta-analysis [22,24,45,47,48,50,51,54-57]. The remaining 4 studies $[46,49,52,53]$ were excluded because no available means and SDs were reported or obtained after contacting the authors. A total of 7 studies focused on patients with asthma
[23,25,58-62]. Of the 7 asthma studies with available data, 5 were pooled into a meta-analysis [25,58,60-62]. The other 2 studies were not included in the meta-analysis because of the lack of means and SDs after contacting the authors.

Figure 1. PRISMA (Preferred Reporting Items for Systematic Reviews and Meta-analyses) flowchart of the systematic review and meta-analysis. COPD: chronic obstructive pulmonary disease; RCT: randomized controlled trial.

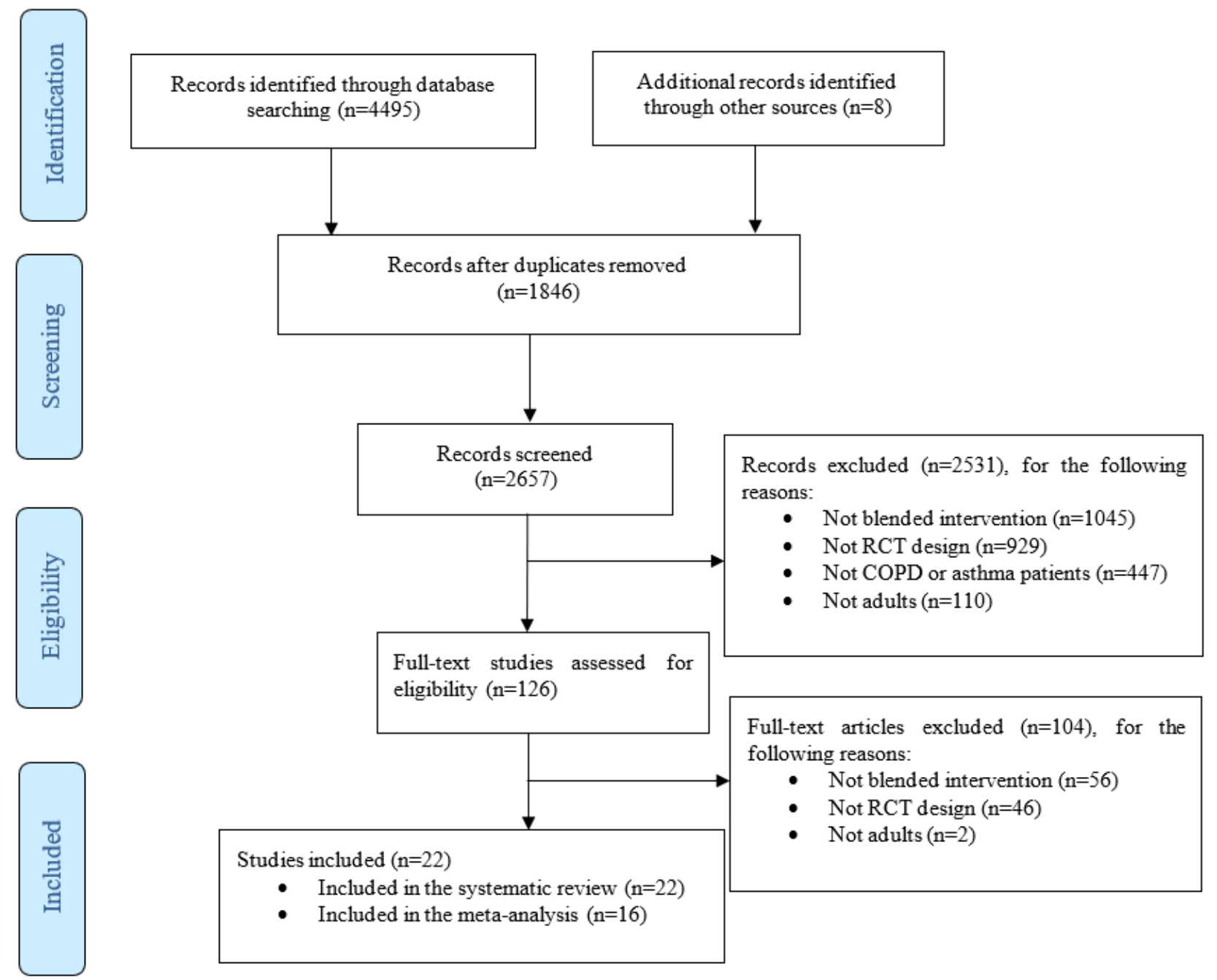

\section{Study Characteristics}

A total of 15 COPD studies [22,24,45-57] were published between 2006 and 2020 and were conducted in China $(n=5)$ [48,54-57], United States ( $=2)$ [24,51], Denmark $(n=2)$ [49,52], Canada $(n=1)$ [53], England $(n=1)$ [45], Spain $(n=1)$ [22], Germany $(n=1)$ [50], Australia $(n=1)$ [46], and 1 in both Spain and Belgium [47]. The sample size ranged from 39 to 242 (with a total sample size of 1477). The average age of patients with COPD ranged from 64.10 to 73.50 years. Of the 15 COPD studies, 8 had UC as a CG [22,24,46,47,49,54,56,57], 5 had a visit as $\mathrm{CG}$ (meaning that the health care provider visited the patients' home or patients visited the PC or SC) $[45,48,51,52,54]$, and 2 studies had both $\mathrm{UC}$ and visits in the CG [50,53]. The settings were home and SC $(n=9)$ $[22,24,46,47,53-57]$, home care $(n=2)[45,48]$, and home care and PC $(n=4)$ [49-52]. The duration of the blended self-management interventions ranged from 4 to 48 weeks, with a mean of 22.13 weeks (SD 16.20). The follow-up duration ranged from 17 to 48 weeks.

Seven asthma studies [23,25,58-63] were published from 2003 to 2020 and were conducted in the Netherlands $(n=3)[25,61,62]$, Germany $(n=1)$ [59], England $(n=1)$ [23], United States $(n=1)$ [60], and China $(n=1)$ [58]. The study sample size ranged from 16 to 200 (total $\mathrm{N}=527$ ). The mean age of patients with asthma ranged from 24.80 to 52.00 years. CG included UC $(n=4)$ $[23,25,60,62]$ and visits $(n=3)[58,59,61]$. The duration of the blended self-management interventions ranged from 3 to 48 weeks, with a mean of 15.88 weeks (SD 13.48). The follow-up duration ranged from 36 to 120 weeks. An overview of the study characteristics is provided in Table 1. 
Table 1. Study characteristics of chronic obstructive pulmonary disease and asthma studies.

\begin{tabular}{lllllll}
\hline COPD $^{\mathrm{a}}$ and & Country & Participants & Setting & $\begin{array}{l}\text { Participants, mean } \\
\text { (SD) }\end{array}$ & $\begin{array}{l}\text { Gender } \\
\text { (female), } \\
\text { asthma study }(\%)\end{array}$ & $\begin{array}{l}\text { Severity }^{\mathrm{b}} \\
\text { n }\end{array}$
\end{tabular}

\section{COPD (included in the meta-analysis)}

\begin{tabular}{|c|c|c|c|c|c|c|c|c|c|c|c|}
\hline $\begin{array}{l}\text { Bentley et } \\
\text { al [45] }\end{array}$ & England & 25 & 23 & Home & $\begin{array}{l}67.20 \\
(11.60)\end{array}$ & $\begin{array}{l}65.90 \\
(9.40)\end{array}$ & $\mathrm{f}^{\mathrm{f}}$ & - & Home visits & 8 & 32 \\
\hline $\begin{array}{l}\text { Chau et al } \\
{[48]}\end{array}$ & China & 22 & 18 & Home & $\begin{array}{l}73.50 \\
(6.10)\end{array}$ & $\begin{array}{l}72.20 \\
(6.10)\end{array}$ & $1(3)$ & II-IV & Home visits & 8 & - \\
\hline $\begin{array}{l}\text { Casas et al } \\
{[47]}\end{array}$ & $\begin{array}{l}\text { Spain and Bel- } \\
\text { gium }\end{array}$ & 65 & 90 & $\begin{array}{l}\text { Home } \\
\text { and } \mathrm{SC}^{\mathrm{g}}\end{array}$ & $\begin{array}{l}70.00 \\
(90.00)\end{array}$ & $\begin{array}{l}72.00 \\
(90.00)\end{array}$ & $26(16.8)$ & I-IV & $\mathrm{UC}^{\mathrm{h}}$ & 4 & 48 \\
\hline $\begin{array}{l}\text { Garcia et al } \\
{[22]}\end{array}$ & Spain & 21 & 41 & $\begin{array}{l}\text { Home } \\
\text { and SC }\end{array}$ & $\begin{array}{l}73.00 \\
(6.00)\end{array}$ & $\begin{array}{l}74.00 \\
(8.00)\end{array}$ & $8(13)$ & - & $\mathrm{UC}$ & 48 & - \\
\hline $\begin{array}{l}\text { Jehn et al } \\
{[50]}\end{array}$ & Germany & 32 & 30 & $\begin{array}{l}\text { Home } \\
\text { and } \mathrm{PC}^{\mathrm{i}}\end{array}$ & $\begin{array}{l}64.10 \\
(10.90)\end{array}$ & $\begin{array}{l}69.10 \\
(9.20)\end{array}$ & $14(23)$ & II-IV & $\begin{array}{l}\mathrm{UC}+\mathrm{PC} \text { vis- } \\
\text { its }\end{array}$ & 36 & - \\
\hline $\begin{array}{l}\text { Koff et al } \\
{[24]}\end{array}$ & United States & 20 & 20 & $\begin{array}{l}\text { Home } \\
\text { and SC }\end{array}$ & $\begin{array}{l}66.60 \\
(9.10)\end{array}$ & $\begin{array}{l}65.00 \\
(8.20)\end{array}$ & $21(53)$ & III-IV & $\mathrm{UC}$ & 12 & 一 \\
\hline $\begin{array}{l}\text { Nguyen et } \\
\text { al [51] }\end{array}$ & United States & 19 & 20 & $\begin{array}{l}\text { Home } \\
\text { and PC }\end{array}$ & $\begin{array}{l}68.00 \\
(8.30)\end{array}$ & $\begin{array}{l}70.90 \\
(8.60)\end{array}$ & $17(44)$ & - & Home visits & 24 & - \\
\hline $\begin{array}{l}\text { Wang et al } \\
{[54]}\end{array}$ & China & 55 & 65 & $\begin{array}{l}\text { Home } \\
\text { and SC }\end{array}$ & $\begin{array}{l}69.30 \\
(7.80)\end{array}$ & $\begin{array}{l}71.90 \\
(8.10)\end{array}$ & $63(52.5)$ & II-IV & $\mathrm{UC}$ & 24 & 48 \\
\hline $\begin{array}{l}\text { Wang et al } \\
\text { [55] }\end{array}$ & China & 39 & 39 & $\begin{array}{l}\text { Home } \\
\text { and SC }\end{array}$ & $\begin{array}{l}63.20 \\
(7.50)\end{array}$ & $\begin{array}{l}64.40 \\
(7.00)\end{array}$ & $23(30)$ & $\begin{array}{l}\text { Mostly } \\
\text { II-IV }\end{array}$ & $\mathrm{SC}$ visits & 48 & - \\
\hline $\begin{array}{l}\text { Wei et al } \\
{[56]}\end{array}$ & China & 42 & 45 & $\begin{array}{l}\text { Home } \\
\text { and SC }\end{array}$ & $\begin{array}{l}65.20 \\
(8.10)\end{array}$ & $\begin{array}{l}63.90 \\
(6.20)\end{array}$ & - & I-IV & $\mathrm{UC}$ & 24 & 48 \\
\hline $\begin{array}{l}\text { Xin et al } \\
{[57]}\end{array}$ & China & 114 & 113 & $\begin{array}{l}\text { Home } \\
\text { and SC }\end{array}$ & $\begin{array}{l}64.20 \\
(14.20)\end{array}$ & $\begin{array}{l}64.60 \\
(14.50)\end{array}$ & $\begin{array}{l}141 \\
(62.1)\end{array}$ & - & $\mathrm{UC}$ & 48 & - \\
\hline \multicolumn{12}{|c|}{ PD (not included in the meta-analysis) } \\
\hline $\begin{array}{l}\text { Cameron et } \\
\text { al [46] }\end{array}$ & Australia & 35 & 30 & $\begin{array}{l}\text { Home } \\
\text { and SC }\end{array}$ & $\begin{array}{l}68.00 \\
(9.90)\end{array}$ & $\begin{array}{l}70.00 \\
(6.80)\end{array}$ & - & I-IV & $\mathrm{UC}$ & 8 & 17 \\
\hline $\begin{array}{l}\text { Haesum et } \\
\text { al [49] }\end{array}$ & Denmark & 47 & 43 & $\begin{array}{l}\text { Home } \\
\text { and PC }\end{array}$ & $\begin{array}{l}70.20 \\
(9.00)\end{array}$ & $\begin{array}{l}69.50 \\
(10.10)\end{array}$ & $47(52)$ & I-IV & $\mathrm{UC}$ & 4 & 40 \\
\hline $\begin{array}{l}\text { Sorknaes et } \\
\text { al [52] }\end{array}$ & Denmark & 121 & 121 & $\begin{array}{l}\text { Home } \\
\text { and PC }\end{array}$ & $\begin{array}{l}71.00 \\
(10.00)\end{array}$ & $\begin{array}{l}72.00 \\
(9.00)\end{array}$ & - & I-IV & $\mathrm{PC}$ visits & 12 & 26 \\
\hline $\begin{array}{l}\text { Stamenova } \\
\text { et al [53] }\end{array}$ & Canada & 41 & 41 & $\begin{array}{l}\text { Home } \\
\text { and SC }\end{array}$ & $\begin{array}{l}71.98 \\
(9.52)\end{array}$ & $\begin{array}{l}71.76 \\
(7.28)\end{array}$ & $36(44)$ & II-IV & SC visits & 24 & - \\
\hline $\begin{array}{l}\text { Stamenova } \\
\text { et al [53] }\end{array}$ & Canada & 41 & 40 & $\begin{array}{l}\text { Home } \\
\text { and SC }\end{array}$ & $\begin{array}{l}71.98 \\
(9.52)\end{array}$ & $\begin{array}{l}72.78 \\
(9.16)\end{array}$ & $37(46)$ & II-IV & UC & 24 & - \\
\hline \multicolumn{11}{|c|}{ hma (included in the meta-analysis) } & \\
\hline $\begin{array}{l}\text { Cao et al } \\
{[58]}\end{array}$ & China & 37 & 30 & $\begin{array}{l}\text { Home } \\
\text { and SC }\end{array}$ & $\begin{array}{l}39.10 \\
(14.30)\end{array}$ & $\begin{array}{l}41.40 \\
(12.00)\end{array}$ & $52(78)$ & - & $\mathrm{SC}$ visits & 12 & - \\
\hline $\begin{array}{l}\text { Ostojic et } \\
\text { al [60] }\end{array}$ & United States & 8 & 8 & $\begin{array}{l}\text { Home } \\
\text { and PC }\end{array}$ & $\begin{array}{l}24.80 \\
(6.30)\end{array}$ & $\begin{array}{l}24.50 \\
(7.00)\end{array}$ & $7(44)$ & $\mathrm{M}^{\mathrm{j}}$ & $\mathrm{UC}$ & 16 & - \\
\hline $\begin{array}{l}\text { Türk et al } \\
\text { [61] }\end{array}$ & $\begin{array}{l}\text { The Nether- } \\
\text { lands }\end{array}$ & 7 & 10 & $\mathrm{SC}$ & $\begin{array}{l}41.57 \\
(12.54)\end{array}$ & $\begin{array}{l}41.90 \\
(8.58)\end{array}$ & $13(77)$ & - & $\mathrm{SC}$ visits & 12 & 48 \\
\hline $\begin{array}{l}\text { Türk et al } \\
{[61]}\end{array}$ & $\begin{array}{l}\text { The Nether- } \\
\text { lands }\end{array}$ & 14 & 10 & $\mathrm{SC}$ & $\begin{array}{l}41.57 \\
(9.73)\end{array}$ & $\begin{array}{l}41.90 \\
(8.58)\end{array}$ & $19(79)$ & - & $\mathrm{SC}$ visits & 12 & 48 \\
\hline $\begin{array}{l}\text { van der } \\
\text { Meer et al } \\
{[25]}\end{array}$ & $\begin{array}{l}\text { The Nether- } \\
\text { lands }\end{array}$ & 101 & 99 & $\begin{array}{l}\text { Home } \\
\text { and SC }\end{array}$ & $\begin{array}{l}36.00 \\
(19.00 \\
50.00)\end{array}$ & $\begin{array}{l}37.00 \\
(18.00 \\
50.00)\end{array}$ & $\begin{array}{l}139 \\
(69.5)\end{array}$ & - & $\mathrm{UC}$ & 12 & 36 \\
\hline
\end{tabular}




\begin{tabular}{|c|c|c|c|c|c|c|c|c|c|c|c|}
\hline \multirow[t]{2}{*}{$\begin{array}{l}\text { COPD }^{a} \text { and } \\
\text { asthma study }^{b}\end{array}$} & \multirow[t]{2}{*}{ Country } & \multicolumn{2}{|c|}{ Participants } & \multirow[t]{2}{*}{ Setting } & \multicolumn{2}{|c|}{$\begin{array}{l}\text { Participants, mean } \\
\text { (SD) }\end{array}$} & \multirow{2}{*}{$\begin{array}{l}\text { Gender } \\
\text { (female), } \\
\mathrm{n}(\%)\end{array}$} & \multirow[t]{2}{*}{ Severity ${ }^{c}$} & \multirow[t]{2}{*}{$\mathrm{CG}^{\mathrm{d}}$} & \multirow{2}{*}{$\begin{array}{l}\text { Interven- } \\
\text { tion } \\
\text { (weeks) }\end{array}$} & \multirow{2}{*}{$\begin{array}{l}\text { Follow- } \\
\text { up } \\
\text { (weeks) }\end{array}$} \\
\hline & & $\mathrm{IG}^{\mathrm{e}}$ & CG & & IG & CG & & & & & \\
\hline $\begin{array}{l}\text { van Gaalen } \\
\text { et al [62] }\end{array}$ & $\begin{array}{l}\text { The Nether- } \\
\text { lands }\end{array}$ & 47 & 60 & $\begin{array}{l}\text { Home } \\
\text { and SC }\end{array}$ & $\begin{array}{l}36.00 \\
(8.70)\end{array}$ & $\begin{array}{l}37.00 \\
(8.00)\end{array}$ & $76(71.0)$ & - & $\mathrm{UC}$ & 48 & 120 \\
\hline \multicolumn{12}{|c|}{ Asthma (not included in the meta-analysis) } \\
\hline $\begin{array}{l}\text { Barbanel et } \\
\text { al [23] }\end{array}$ & England & 12 & 12 & $\begin{array}{l}\text { Home } \\
\text { and SC }\end{array}$ & $\begin{array}{l}45.00 \\
(17.00)\end{array}$ & $\begin{array}{l}47.00 \\
(17.00)\end{array}$ & $13(54)$ & - & $\mathrm{UC}$ & 12 & - \\
\hline $\begin{array}{l}\text { Kohler et } \\
\text { al [59] }\end{array}$ & Germany & 41 & 41 & $\begin{array}{l}\text { Home } \\
\text { and PC }\end{array}$ & $\begin{array}{l}49.00 \\
(12.00)\end{array}$ & $\begin{array}{l}52.00 \\
(8.00)\end{array}$ & $32(39)$ & - & PC $^{\mathrm{i}}$ visits & 3 & - \\
\hline
\end{tabular}

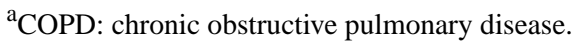

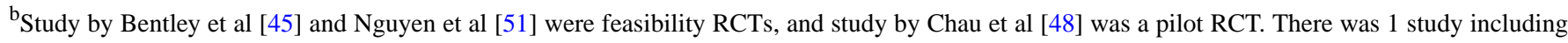
1 intervention group and 2 control groups (study by Stamenova et al [53]). Study by Türk et al [61] included 2 intervention groups and 1 control group. ${ }^{\mathrm{c}}$ COPD severity was classified according to GOLD (Global Initiative for Chronic Obstructive Lung Disease) classification. Asthma severity was classified by the physician diagnosis.

${ }^{\mathrm{d}} \mathrm{CG}$ : control group.

e IG: intervention group.

${ }^{\mathrm{f}}$ Not reported in the study.

${ }_{\mathrm{SC}}$ : secondary care.

$\mathrm{h}_{\mathrm{UC}}$ : usual care.

${ }^{\mathrm{i}} \mathrm{PC}$ : primary care.

${ }^{\mathrm{j}} \mathrm{M}$ : moderate severity.

\section{Quality Assessment}

\section{Methodological Quality}

The ROB is summarized in Table 2. Among the 15 COPD studies, the overall ROB was rated as some concerns in 10 studies [22,46,47,49,52-57] and high in 5 studies [24,45,48,50,51]. In addition, 2 studies had some concerns in the randomization process [48,50], and 13 studies showed a low ROB in the randomization process [22,24,45-47,49,51-57]. The majority of the studies showed some concerns [22,45-47,49,51-57], whereas 3 studies showed high risk from intended intervention $[24,48,50]$. A low ROB due to missing outcome data was found in 14 studies [22,24,45,46,48-57], whereas 1 study showed some concerns [47]. The ROB in the measurement of the outcome had some concerns in 13 studies
[22,24,45,46,48-51,53-57] and a low ROB in 2 studies [47,52]. A low ROB in the selection of the reported result was found in the majority of studies [22,24,46-50,52-57], and 2 studies had some concerns $[45,51]$.

In asthma studies, the overall ROB indicated some concerns in 4 studies [23,25,61,62] and high risk in 3 studies [58-60]. Four studies showed a low ROB in the randomization process [23,25,61,62], and 3 studies showed some concerns [58-60]. All studies indicated some concerns due to deviations from the intended intervention [23,25,58-62]. In total, 6 studies showed a low ROB outcome data [23,25,59-62], and 1 study had some concerns due to missing outcome data [58]. All studies showed some concerns in the measurement of the outcomes and low ROB in the selection of the reported results [23,25,58-62]. 
Table 2. Risk of bias judgments for chronic obstructive pulmonary disease and asthma randomized controlled trials.

\begin{tabular}{|c|c|c|c|c|c|c|}
\hline $\mathrm{COPD}^{\mathrm{a}}$ or asthma study & $\begin{array}{l}\text { Bias arising from the } \\
\text { randomization pro- } \\
\text { cess }\end{array}$ & $\begin{array}{l}\text { Bias due to devia- } \\
\text { tions from the in- } \\
\text { tended intervention }\end{array}$ & $\begin{array}{l}\text { Bias due to } \\
\text { missing out- } \\
\text { come data }\end{array}$ & $\begin{array}{l}\text { Bias in measure- } \\
\text { ment of the out- } \\
\text { come }\end{array}$ & $\begin{array}{l}\text { Bias in selec- } \\
\text { tion of the re- } \\
\text { ported result }\end{array}$ & Overall bias \\
\hline \multicolumn{7}{|l|}{ COPD } \\
\hline Bentley et al [45] & $L^{b}$ & $S^{c}$ & $\mathrm{~L}$ & $S$ & $S$ & $\mathrm{H}^{\mathrm{d}}$ \\
\hline Cameron et al [46] & $\mathrm{L}$ & $S$ & $\mathrm{~L}$ & S & $\mathrm{L}$ & $S$ \\
\hline Casas et al [47] & $\mathrm{L}$ & $S$ & $S$ & $\mathrm{~L}$ & $\mathrm{~L}$ & $S$ \\
\hline Chau et al [48] & $S$ & $\mathrm{H}$ & $\mathrm{L}$ & $S$ & $\mathrm{~L}$ & $\mathrm{H}$ \\
\hline Garcia [22] & $\mathrm{L}$ & $S$ & $\mathrm{~L}$ & $S$ & $\mathrm{~L}$ & $S$ \\
\hline Haesum et al [49] & $\mathrm{L}$ & $S$ & $\mathrm{~L}$ & $S$ & $\mathrm{~L}$ & $\mathrm{~S}$ \\
\hline Jehn et al [50] & $S$ & $\mathrm{H}$ & $\mathrm{L}$ & $S$ & $\mathrm{~L}$ & $\mathrm{H}$ \\
\hline Koff et al [24] & $\mathrm{L}$ & $\mathrm{H}$ & $\mathrm{L}$ & $S$ & $\mathrm{~L}$ & $\mathrm{H}$ \\
\hline Nguyen et al [51] & $\mathrm{L}$ & $S$ & $\mathrm{~L}$ & $S$ & $S$ & $\mathrm{H}$ \\
\hline Sorknaes et al [52] & $\mathrm{L}$ & $S$ & $\mathrm{~L}$ & $\mathrm{~L}$ & $\mathrm{~L}$ & $S$ \\
\hline Stamenova et al [53] & $\mathrm{L}$ & S & $\mathrm{L}$ & $S$ & $\mathrm{~L}$ & $S$ \\
\hline Wang et al [54] & $\mathrm{L}$ & S & $\mathrm{L}$ & $S$ & $\mathrm{~L}$ & $S$ \\
\hline Wang et al [55] & $\mathrm{L}$ & $S$ & $\mathrm{~L}$ & $\mathrm{~S}$ & $\mathrm{~L}$ & $S$ \\
\hline Wei et al [56] & $\mathrm{L}$ & S & $\mathrm{L}$ & $S$ & $\mathrm{~L}$ & $S$ \\
\hline Xin et al [57] & $\mathrm{L}$ & $S$ & $\mathrm{~L}$ & $S$ & $\mathrm{~L}$ & $S$ \\
\hline \multicolumn{7}{|l|}{ Asthma } \\
\hline Barbanel et al [23] & $\mathrm{L}$ & S & $\mathrm{L}$ & S & $\mathrm{L}$ & S \\
\hline Cao et al [58] & $S$ & $S$ & $\mathrm{~S}$ & S & $\mathrm{L}$ & $\mathrm{H}$ \\
\hline Kohler et al [59] & $S$ & $S$ & $\mathrm{~L}$ & S & $\mathrm{L}$ & $\mathrm{H}$ \\
\hline Ostojic et al [60] & $S$ & $S$ & $\mathrm{~L}$ & S & $\mathrm{L}$ & $\mathrm{H}$ \\
\hline Türk et al [61] & $\mathrm{L}$ & S & $\mathrm{L}$ & S & $\mathrm{L}$ & $S$ \\
\hline van der Meer et al [25] & $\mathrm{L}$ & S & $\mathrm{L}$ & S & $\mathrm{L}$ & $S$ \\
\hline van Gaalen et al [62] & $\mathrm{L}$ & $S$ & $\mathrm{~L}$ & S & $\mathrm{L}$ & $S$ \\
\hline
\end{tabular}

${ }^{\mathrm{a} C O P D}$ : chronic obstructive pulmonary disease.

${ }^{\mathrm{b}} \mathrm{L}$ : low risk of bias.

${ }^{\mathrm{c}} \mathrm{S}$ : some concerns.

${ }^{\mathrm{d}} \mathrm{H}$ : high risk of bias.

\section{Quality of Evidence}

In COPD studies, 19 different outcome measures were included (ie, exercise capacity, dyspnea, lung function, QoL, admission rate, exacerbation frequency, mortality, BMI, visits, satisfaction, costs, smoking, medication adherence, self-management ability, physical activity, psychosocial, symptom management, nutrition, and alcohol). Two outcome measures were rated as high quality of evidence (ie, exercise capacity and mortality), 1 measure had a moderate quality of evidence (ie, admission rate), 6 had a low quality of evidence (ie, dyspnea, lung function, QoL, visits, satisfaction, and physical activity), and the other 10 showed very low quality of evidence (exacerbation frequency, BMI, adherence, self-management ability, smoking, costs, psychosocial, symptom management, nutrition, and alcohol). In asthma studies, 10 different outcome measures were included (ie, admission rate, BMI, exercise capacity, asthma control, lung function, QoL, asthma knowledge, adherence, visits, and exacerbation frequency). Of the 10 outcomes, 7 were rated as having very low quality of evidence (ie, admission rate, BMI, exercise capacity, asthma knowledge, adherence, visits, and exacerbation frequency). Asthma control, lung function, and QoL were rated as having moderate quality of evidence (Multimedia Appendix 2 [22-25,45-62]).

\section{Intervention Characteristic}

\section{Category of the Blended Self-Management Intervention}

In COPD studies, 5 blended self-management intervention combinations were discussed: (1) multiple component eHealth and an individual face-to-face intervention $(n=6)$ [49-53,57], (2) internet-assisted intervention and an individual face-to-face intervention $(n=5)[22,45,47,48,54]$, (3) multiple component plus an individual and group face-to-face intervention $(n=1)$ 
[49], (4) mobile applications and an individual face-to-face intervention $(n=2)[55,56]$, and (5) mobile applications and an individual plus group face-to-face intervention $(n=1)$ [46].

In asthma studies, 2 blended self-management intervention combinations were discussed: (1) mobile application and individual face-to-face intervention $(\mathrm{n}=3)[23,58,60]$ and $(2)$ internet-assisted intervention and the group face-to-face intervention $(n=4)[25,59,61,62]$. Detailed information on the interventions in the COPD and asthma studies is shown in Table 3. 
Table 3. Description of the blended self-management interventions in chronic obstructive pulmonary disease and asthma studies.

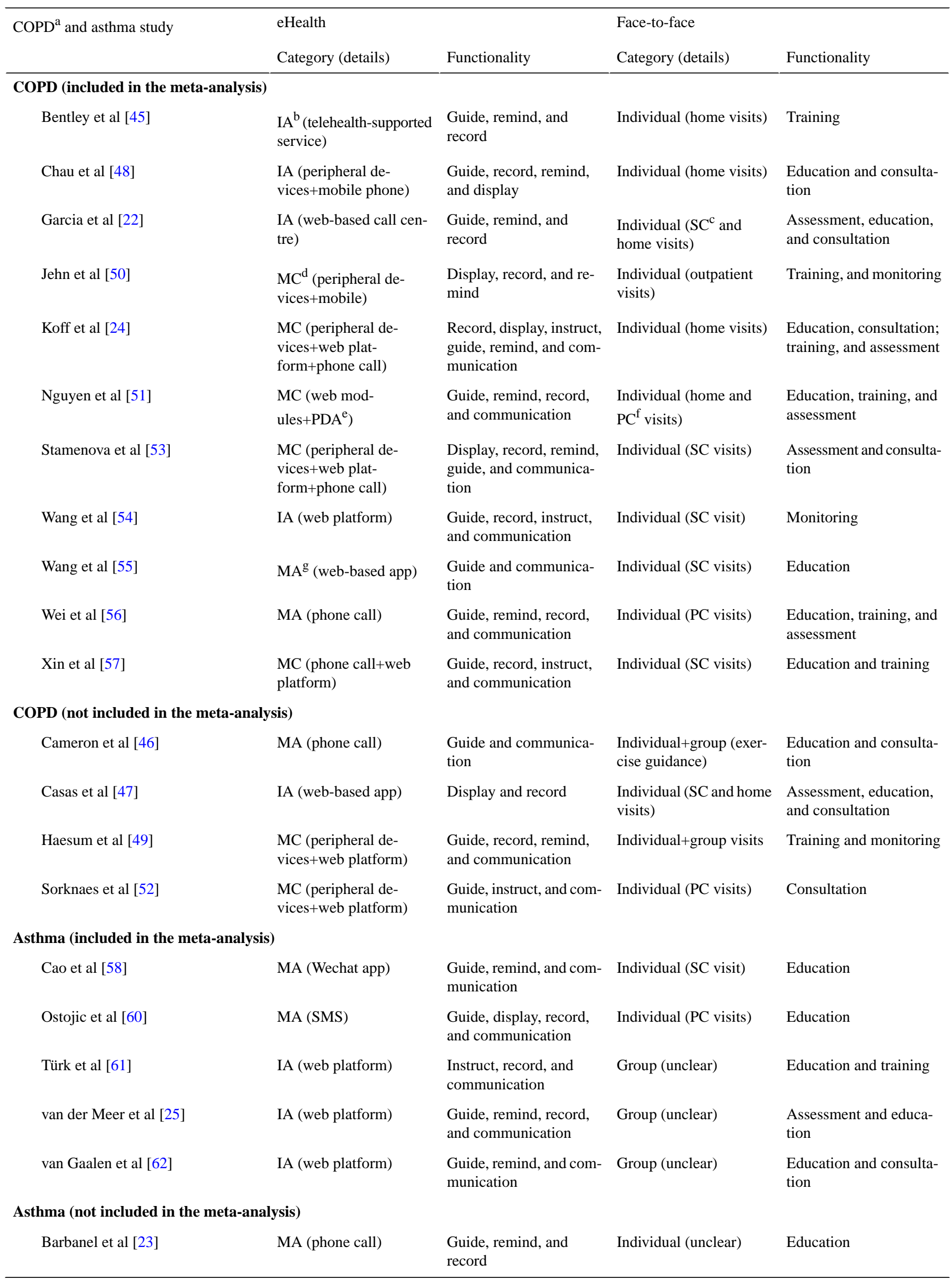




\begin{tabular}{cllll}
\hline COPD $^{\mathrm{a}}$ and asthma study & eHealth & & Face-to-face \\
& Category (details) & Functionality & Category (details) & Functionality \\
\hline Kohler et al [59] & IA (web platform) & $\begin{array}{l}\text { Guide, record, and com- } \\
\text { munication }\end{array}$ & Group (unclear) & Education and training \\
\hline
\end{tabular}

${ }^{\mathrm{a}} \mathrm{COPD}$ : chronic obstructive pulmonary disease.

${ }^{\mathrm{b}} \mathrm{IA}$ : internet-assisted.

${ }^{\mathrm{c}} \mathrm{SC}$ : secondary care.

${ }^{\mathrm{d}} \mathrm{MC}$ : multiple component.

${ }^{\mathrm{e}} \mathrm{PDA}$ : personal digital assistant.

${ }^{\mathrm{f}} \mathrm{PC}$ : primary care.

${ }^{\mathrm{g}}$ MA: mobile application.

\section{BCTs of the Blended Self-Management Intervention}

In COPD studies, the number of BCTs used in the interventions ranged from 3 to 10, with a mean of 6.42 (SD 1.99). General information, Provide feedback on performance, Prompt self-monitoring/tracking, and Problem-solving/barrier were included in 15 studies [22,24,45-57]. Action planning [22,46,47,51-54,56,57] and Motivational approach [22,24,46,47,50-52,54,55] were included in 9 studies, respectively. Prompt review of behavioural goals were included in 7 studies $[22,46,47,49,51,53,54]$. Goal setting was used in 6 studies [22,46,47,51,53,54]. Social support was reported in 4 studies [22,47,51,55], and Emotional control training was used in 2 studies [46,51].

In asthma studies, the number of BCTs ranged from 4 to 10 , with a mean of 6.29 (SD 2.63). General information, Prompt self-monitoring/ tracking, and Problem-solving/barrier were used in all 7 studies [23,25,58-62]. Provide feedback on performance was used in 6 studies [25,58-62]. Action planning and Motivational approach were used in 4 studies [23,25,61,62]. Goal setting and Prompt review of behavioural goals were used in 3 studies [25,61,62], Social support was used in 2 studies [61,62], and Emotional control training was used in 1 study [61] (Multimedia Appendix 3 [22-25,45-62])

\section{Effects of the Interventions}

\section{Systematic Review}

In COPD studies, the following 3 health-related effectiveness outcomes were reported: mortality [45,47,52], exacerbation frequency [50,57], and BMI [22]. Regarding outcome mortality, none of the 3 studies reported any effect $[45,47,52]$. Regarding outcome exacerbation frequency, both studies [50,57] found that the blended self-management intervention reduced the exacerbation frequency $(\mathrm{RR}=0.38$; 95\% CI 0.26-0.56). A study on BMI reported that blended self-management intervention had a significant effect on BMI $(d=0.81 ; 95 \%$ CI $0.25-1.34)$ [22]. Moreover, 11 different process outcomes were studied: number of visits (including home visits, $\mathrm{PC}$ visits, and SC visits; $\mathrm{n}=3)[47,48,50]$, satisfaction with the intervention $(\mathrm{n}=3)$ $[22,24,48]$, medication adherence $(n=3)[22,56,57]$, costs $(n=2)$ $[24,45]$, smoking $(n=2)[22,46]$, self-management ability $(n=2)$ [51,55], physical activity $(n=2)[22,51]$, nutrition $(n=1)[46]$, alcohol $(n=1)$ [46], psychosocial management $(n=1)$ [46], and symptom management $(n=1)$ [46]. Of the 3 studies, 2 showed

a moderate effect $(d=0.73 ; 95 \%$ CI $0.50-0.96)$ [56,57], whereas the other study reported a mixed effect on medication adherence [22]. Regarding the outcome self-management ability, 1 reported a large effect $(d=1.15 ; 95 \%$ CI $0.66-1.62)$ [55], and the other study showed no effect [51]. No effect was found on the other process outcome indicators. In asthma studies, 4 health-related effectiveness outcomes were reported: admission rate [60], BMI [61], exercise capacity [61], and exacerbation frequency [25]. No effect was found on the admission rate and exacerbation frequency. A large effect was found in BMI $(d=1.42 ; 95 \% \mathrm{CI}$ $0.28-2.42)$ and exercise capacity ( $d=1.50 ; 95 \%$ CI $0.35-2.50)$. Three process outcomes were reported: asthma knowledge $(\mathrm{n}=2)$ [25,59], visits $(n=2)[25,60]$, and adherence (therapy and medication adherence; $n=2)[25,60]$. No effect was found on any of the process outcome indicators.

\section{Meta-analysis}

A total of 11 studies focusing on patients with COPD were included in the meta-analysis [22,24,45,48,50,51,53-57]. The following health-related effectiveness outcomes were included: exercise capacity, dyspnea, lung function, QoL, and admission rate. Three studies reported walking distance as an indicator of exercise capacity [50,51,54]. Blended self-management intervention showed a small effect on the walking distance without significant heterogeneity $(\mathrm{SMD}=0.48 ; 95 \%$ CI $0.10-0.85, \chi_{2=}^{2} 3.3 ; P=.20 ; I^{2}=39 \%$; Figure 2 ). No study was identified as an outlier. Dyspnea was reported in 4 studies $[22,48,51,54]$. It was measured using the dyspnea subscale of the CRQ [48,51], Medical Research Council [22], and the Modified Medical Research Council [54]. Lung function was measured with FEV1\% [48,50,54] and FEV1/FVC (\%) [22] in 4 studies. No significant difference was found in dyspnea and lung function between the IG and CG (Figure 2). No study was identified as an outlier. QoL was reported in 8 studies with SGRQ [22,24,45,54], CAT [50,55,57], and CRQ [51]. A large effect was found on QoL, with substantial heterogeneity (SMD=0.81; 95\% CI 0.11-1.51; $\chi^{2}{ }_{7}=108.4 ; P<.001 ; I^{2}=94 \%$ Figure 3 ). The standardized residual identified 1 study as an outlier [22]. Removal of this study resulted in an increased effect size without decreasing heterogeneity $(\mathrm{SMD}=0.90 ; 95 \% \mathrm{CI}$ $\left.0.15-1.65 ; \chi_{6}^{2}=94.1 ; P<.001 ; I^{2}=94 \%\right)$. Furthermore, blended self-management intervention reduced admission rate with a substantial heterogeneity $\quad(\mathrm{RR}=0.61 ; 95 \%$ CI $0.38-0.97$; 
$\chi^{2}{ }_{5}=17.6 ; \quad P=.003 ; I^{2}=72 \%$; Figure 4). No outliers were identified.

A total of 5 asthma studies were pooled in the meta-analysis [25,58,60-62]. In addition, 3 health-related effectiveness outcomes were included: lung function, QoL, and asthma control. Lung function was reported as FEV1 (\%) [58,61] and $\mathrm{FEV}_{1}$ [25]. Blended self-management intervention showed a small effect on the lung function without significant heterogeneity $\left(\mathrm{SMD}=0.40 ; 95 \%\right.$ CI $0.18-0.62 ; \chi^{2}{ }_{4}=1.5 ; P=.83$; $\left.I^{2}=0 \%\right)$. No study was identified as an outlier. Three studies reported QoL using an asthma QoL questionnaire [25,58,62]. There was a small effect size of the blended self-management intervention on QoL without significant heterogeneity ( $\mathrm{SMD}=0.36 ; 95 \%$ CI $0.21-0.50 ; \chi_{2}^{2}=0.8 ; P=.68 ; I^{2}=0 \%$ ). No study was identified as an outlier. Furthermore, 3 studies reported asthma control using an asthma control questionnaire $[25,58,62]$. A moderate effect was found in the blended intervention self-management group without significant heterogeneity (SMD $=0.67 ; 95 \%$ CI $0.40-0.93 ; \chi_{2}^{2}=3.0 ; P=.23$; $I^{2}=33 \%$; Figure 5). No study was identified as an outlier.

Figure 2. Forest plots for (A) exercise capacity, (B) dyspnea, and (C) lung function in chronic obstructive pulmonary disease studies.

A: Forest plot for exercise capacity

\begin{tabular}{|c|c|c|c|c|c|c|c|c|}
\hline \multirow[b]{2}{*}{ Study or subgroup } & \multicolumn{2}{|c|}{ Intervention group } & \multicolumn{2}{|c|}{ Control group } & \multicolumn{2}{|r|}{ Std.Mean difference } & & \multirow{2}{*}{$\begin{array}{l}\text { Std.Mean difference } \\
\text { IV.Random. } 95 \% \text { CI }\end{array}$} \\
\hline & Mean (SD) & Total & Mean (SD) & Total & Weight & IV.Random.95\%CI & & \\
\hline Jehn et al [50] & $87(65.7)$ & 27 & $23.9(70.3)$ & 25 & $28.2 \%$ & $0.91[0.34-1.49]$ & & $1 \rightarrow$ \\
\hline Nguyen et al [51] & $20(81.84)$ & 19 & $-12(141.51)$ & 20 & $24.8 \%$ & $0.27[-0.36$ to 0.90$]$ & & -5 \\
\hline Wang et al [54] & $19.23(110.29)$ & 55 & $-13.89(91.02)$ & 65 & $47.0 \%$ & $0.33[-0.03$ to 0.69$]$ & & 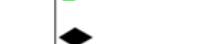 \\
\hline Total $(95 \% \mathrm{Cl})$ & & 101 & & 110 & $100.0 \%$ & $0.48[0.10-0.85]$ & $\begin{array}{ll}-4 & -2\end{array}$ & 2 \\
\hline \multicolumn{8}{|c|}{ Heterogeneity: $\mathrm{Tau}^{2}=0.04 ; \chi_{2}^{2}=3.3(P=.20) ; \mathrm{I}^{2}=39 \% \quad$ Control group } & Intervention group \\
\hline
\end{tabular}

Test for overall effect: $Z=2.51(P=.01)$

B: Forest plot for dyspnea

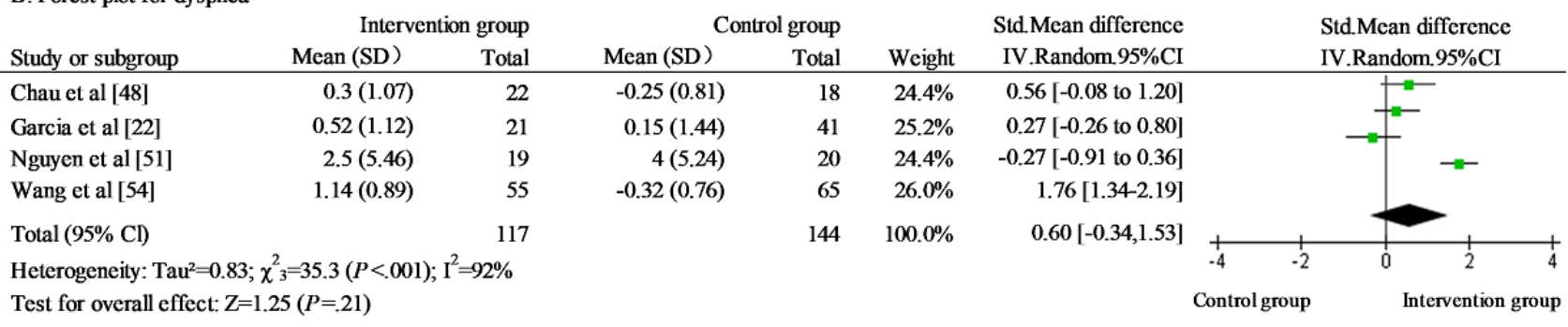

C: Forest plot for lung function

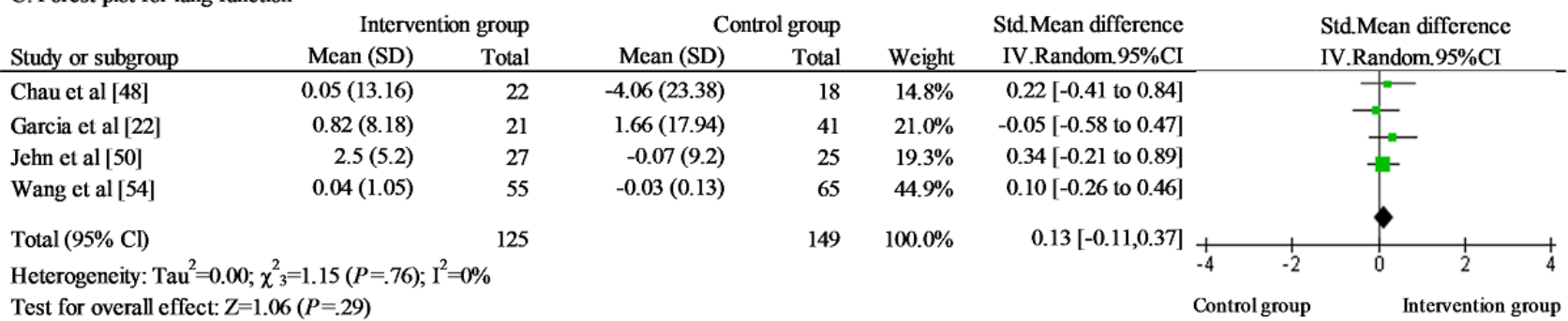

Std: standard; IV: inverse variance

Figure 3. Forest plot for quality of life in chronic obstructive pulmonary disease studies.

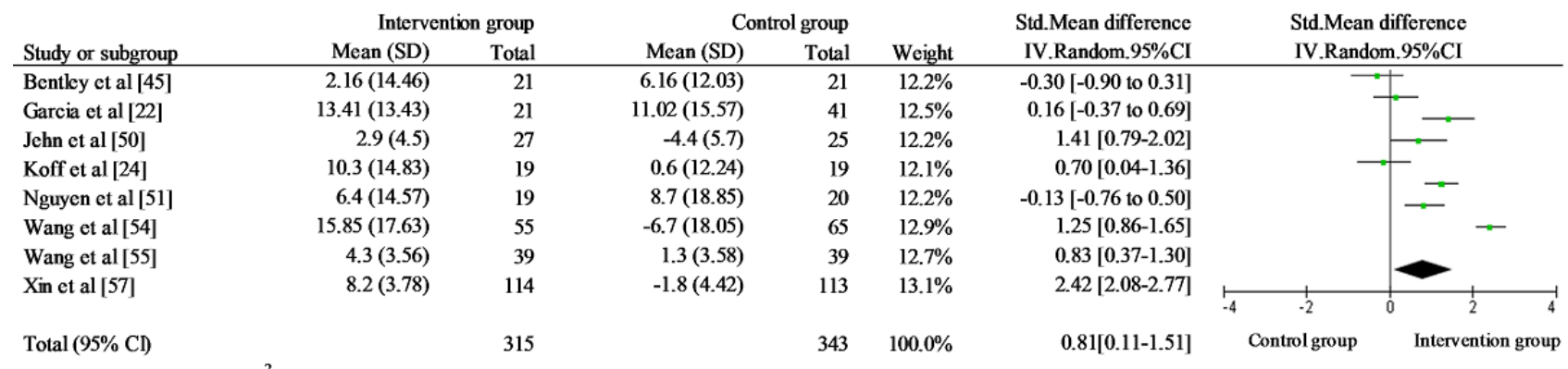

Heterogeneity: Tau $^{2}=0.94 ; \chi^{2}{ }_{7}=108.4(P<.001) ; I^{2}=94 \%$

Test for overall effect: $\mathrm{Z}=2.27(P=.02)$

Std: standard; IV: inverse variance 
Figure 4. Forest plot for admission rate in chronic obstructive pulmonary disease studies.

\begin{tabular}{|c|c|c|c|c|c|c|c|c|c|}
\hline \multirow[b]{2}{*}{ Study or subgroup } & \multicolumn{2}{|c|}{ Intervention group } & \multicolumn{2}{|c|}{ Control group } & \multicolumn{2}{|r|}{ Risk Ratio } & \multirow{2}{*}{\multicolumn{2}{|c|}{$\begin{array}{c}\text { Risk Ratio } \\
\text { M-H.Random. } 95 \% \mathrm{CI}\end{array}$}} & \\
\hline & Events & Total & Events & Total & Weight & M-H.Random. $95 \% \mathrm{CI}$ & & & \\
\hline Bentley et al [45] & 8 & 23 & 4 & 25 & $11.2 \%$ & $2.17[0.75-6.26]$ & -1 & & \\
\hline Cacas et al [47] & 29 & 65 & 60 & 90 & $23.7 \%$ & $0.67[0.49-0.91]$ & $\rightarrow-$ & & \\
\hline Chau et al [48] & 7 & 22 & 3 & 18 & $9.6 \%$ & $1.91[0.57-6.34]$ & & & \\
\hline Jehn et al [50] & 7 & 27 & 22 & 25 & $17.4 \%$ & $0.29[0.15-0.57]$ & & & \\
\hline Wei et al [56] & 16 & 42 & 38 & 45 & $22.0 \%$ & $0.45[0.30-0.68]$ & & & \\
\hline Xin et al [57] & 9 & 114 & 24 & 113 & $16.2 \%$ & $0.37[0.18-0.76]$ & & & \\
\hline Total $(95 \% \mathrm{Cl})$ & & 293 & & 316 & $100.0 \%$ & $0.61[0.38-0.97]$ & & & \\
\hline Heterogeneity: Tau & $=17.6(\mathrm{I}$ & 3); $\mathrm{I}^{2}=$ & & & & & $\begin{array}{l}0.05 \quad 0.2 \\
\text { Control group }\end{array}$ & ${ }^{1}$ Interventio & $\begin{array}{l}5 \\
\text { on group }\end{array}$ \\
\hline
\end{tabular}

Test for overall effect: $\mathrm{Z}=2.08(P=.04)$

M-H: Mantel-Haenszel

Figure 5. Forest plots for (A) lung function, (B) quality of life, and (C) asthma control in asthma studies.

A: Forest plot for lung function

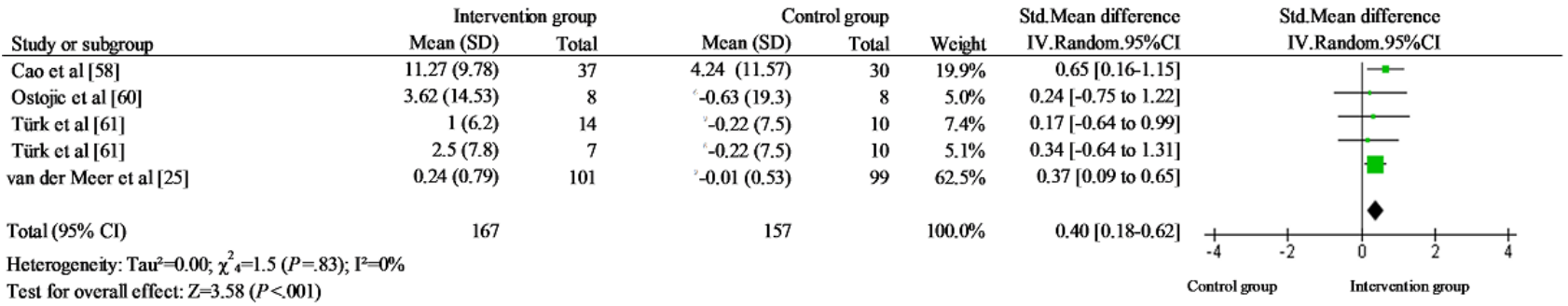

B: Forest plot for quality of life

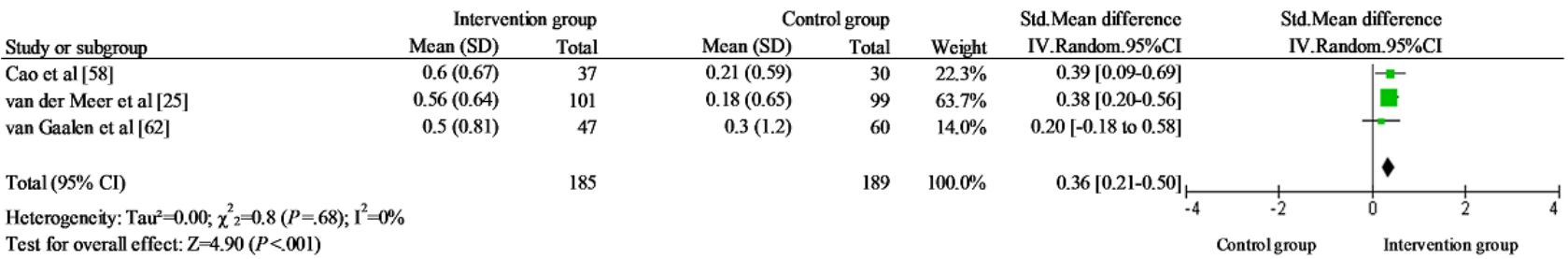

C: Forest plot for asthma control

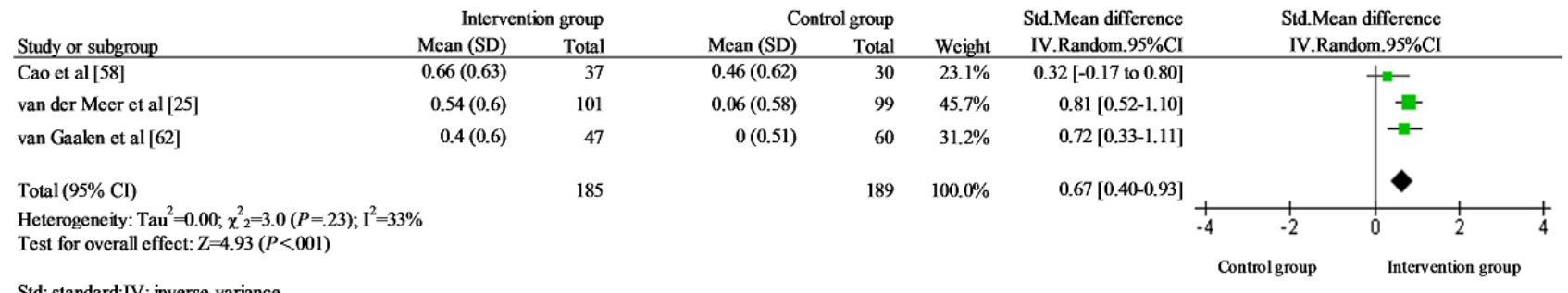

\section{Discussion}

\section{Principal Findings}

This systematic review and meta-analysis assessed the effectiveness of blended self-management interventions on health-related effectiveness and process outcome indicators in patients with COPD or asthma. Of the 22 studies that were included in the systematic review, 15 were about COPD and 7 were about asthma.

Studies focusing on COPD patients included 3 different health-related effectiveness outcome indicators, and mixed effects were observed. No effect was observed on mortality. A positive effect was observed for exacerbation frequency and BMI. In total, 11 different process outcome indicators were studied (eg, medication adherence and self-management ability). Of the 3 studies, 2 reported a moderate effect on adherence. A positive effect was found in 1 of the 2 studies on self-management ability. No effects were found on the other process outcomes. Eleven COPD studies were included in the meta-analysis. Blended self-management interventions did not have a significant effect on dyspnea or lung function. Still, they did result in a small improvement in exercise capacity and a moderate improvement in QoL and decreased the admission rate. Overall, the majority of studies had some concerns about the ROB assessment.

The asthma studies included 4 health-related effectiveness outcomes. Large effects were observed in BMI and exercise capacity. There was no effect on the admission rate and exacerbation frequency. Three process outcomes were studied 
(ie, visits, intervention and medication adherence, and asthma knowledge). No effect was found on any of the process outcomes. Five asthma studies were included in the meta-analysis. Blended self-management intervention showed a small effect on lung function and QoL, and a moderate effect was found on asthma control. Half of the studies reported some concerns, whereas others showed a high ROB assessment.

The meta-analysis suggested that blended self-management interventions can effectively improve the exercise capacity of patients with COPD. This result was in line with another systematic review that examined the effect of COPD disease management programs, including eHealth and face-to-face components [64]. However, this finding was not consistent with a systematic review of the effect of telehealth in patients with COPD [65]. This may be because the blended programs, contrary to the telehealth programs, were likely to promote exercise capacity using various BCTs, including providing information and instruction on the behavior, self-monitoring, and providing feedback on performance by eHealth and face-to-face intervention [64]. This meta-analysis also showed that blended self-management interventions had a positive effect on QoL, which was in line with the findings of a meta-analysis that investigated the effect of COPD self-management interventions, including various self-management programs [66]. Blended self-management intervention significantly decreased admission rates. This finding was consistent with a previous meta-analysis [67], in which the effect of integrated care from health care providers with or without eHealth was identified. This might be because patients increased their self-management ability and acted on exacerbations more promptly if they received self-management intervention with multiple BCTs [68]. However, the blended self-management interventions included in this meta-analysis did not improve dyspnea and lung function, which was consistent with earlier systematic reviews that investigated the implementation of eHealth or manual therapy in patients with COPD $[69,70]$.

Blended self-management intervention showed an inconsistent impact on process outcomes in patients with COPD. To illustrate, internet-assisted eHealth and individual face-to-face intervention showed a positive effect on self-management ability [54], whereas no effect was found in the blended intervention, including multiple eHealth components and individual face-to-face intervention [51]. The findings in this study may show that certain combinations within the blended interventions may be more effective in some outcomes; however, more large-scale studies using different combinations are needed to provide insight into this. There are several potential explanations for the lack of effects in COPD studies included in the systematic review. First, the length of the blended interventions varied among the included studies (ie, ranged from 4 to 48 weeks). The short intervention duration might have been problematic because patients with mild to very severe COPD were included in the studies. Airway obstruction is usually irreversible in those patients, and the duration of the blended interventions might have been too short to accommodate a change in health [71]. Furthermore, it appears that patients did not adhere sufficiently to blended interventions [22]. This lack of adherence might be because eHealth apps are unfamiliar to some patients [18]. We recommend that future studies educate patients on how to use eHealth because eHealth has a positive effect on improving medication adherence [72].

In asthma studies, in line with other systematic reviews focusing on integrated asthma management (ie, the cooperation of community pharmacists and general practitioners or eHealth and face-to-face intervention), the blended interventions had a positive effect on QoL and asthma control $[73,74]$. A previous review focusing on face-to-face interventions in patients with asthma showed that face-to-face intervention did not improve QoL and asthma control [75]. The possible reasons for this improvement could be attributed to the integrated care provided by health care providers. Health care providers can update and refer patients for education, counseling, and guidance with eHealth and face-to-face interventions $[73,74]$. This suggests that, compared with face-to-face interventions, blended interventions or integrated asthma management-where health care providers could refer patients for additional education, counseling, and guidance with eHealth and face-to-face intervention-are more effective. A positive effect was observed on the lung function. This finding was consistent with a meta-analysis that focused on aerobic exercise in patients with asthma [76]. This may be because adequate exercise training is beneficial to lung function. However, due to the limited number of studies included in the meta-analysis, more studies are needed to identify this effect. In this systematic review, limited studies have investigated the effects of blended interventions in patients with asthma. Therefore, the findings should be interpreted cautiously, and future studies with larger sample sizes are needed.

\section{Strengths and Limitations}

Several strengths of this review are worth mentioning. First, a detailed description of the interventions was provided, and a wide range of outcomes was included. The detailed information might provide a helpful direction for the development of effective blended self-management interventions. Second, GRADE was used to assess the quality of evidence regarding the true effect of the blended intervention on patients with COPD and asthma. This quality of evidence assessment could provide a clear and pragmatic interpretation of the recommendations for clinicians and policy makers. Finally, we followed a strict study design and precise data analysis steps. By using a strict and precise process, we wanted to ensure the quality of the systematic review and meta-analysis.

However, several limitations also need to be addressed. First, there was a diversity in the intervention and outcome measurements, which made it difficult to compare the findings. Consequently, there may be statistical heterogeneity in the true effect size. Significant heterogeneity potentially diluted the intervention effect [77]. Second, only a small number of studies reported the same outcome measure, and studies with a small sample size were included. These studies may be underpowered to detect a true effect, and this negatively impacted the validity of these studies. Third, the quality of the evidence ranged from very low to high for all outcomes. The various quality of evidence in the outcomes may weaken the recommendation level for clinicians and researchers because the high 
heterogeneity among studies downgraded the quality of evidence. Fourth, we were not able to assess the risk of publication bias in the meta-analysis because few studies reported on the same outcome [40]. There may be a potential risk of publication bias. Finally, not all studies reported a follow-up. The lack of this reporting made it impossible to examine the long-term intervention effect in a comprehensive way. The results should be interpreted with caution owing to the limitations mentioned above. Larger RCTs are required to provide more insights, especially RCTs examining the effects of blended interventions in patients with asthma. Moreover, data reporting should be performed in an exact, standardized format to enable reliable extraction for future meta-analysis studies.

\section{Conclusions}

The studies focusing on COPD found mixed effects of blended self-management interventions on health-related outcomes, with the strongest evidence found for exercise capacity, QoL, and admission rate. In asthma studies, small to moderate effects were found on asthma control, lung function, and QoL. Overall, blended self-management interventions potentially improve health-related outcomes in patients with COPD and asthma, and more studies are needed to evaluate their effectiveness.

\section{Acknowledgments}

This study was funded by the China Scholarship Council.

\section{Conflicts of Interest}

None declared.

\section{Multimedia Appendix 1}

Search terms.

[DOCX File, 17 KB-Multimedia Appendix 1]

\section{Multimedia Appendix 2}

Grading of Recommendations, Assessment, Development, and Evaluation evidence tables.

[DOCX File, 19 KB-Multimedia Appendix 2]

\section{Multimedia Appendix 3}

Behavior change techniques in the blended self-management interventions.

[DOCX File, 17 KB-Multimedia Appendix 3]

\section{References}

1. Soriano JB, Kendrick PJ, Paulson KR, Gupta V, Vos T, Abrams E. Prevalence and attributable health burden of chronic respiratory diseases, 1990-2017: a systematic analysis for the Global Burden of Disease Study 2017. Lancet Respir Med 2020;8(6):585-596.

2. World HO. Chronic obstructive pulmonary disease (COPD). Geneva, Switzerland: WHO 2015;http:2015.

3. Wang HD, Naghavi M, Allen C, Barber RM, Bhutta ZA, Carter A. Global, regional, and national life expectancy, all-cause mortality, and cause-specific mortality for 249 causes of death, 1980-2015: a systematic analysis for the Global Burden of Disease Study 2015. Lancet 2016 Oct 08;388(10053):1459-1544 [FREE Full text] [doi: 10.1016/S0140-6736(16)31012-1] [Medline: 27733281]

4. Mannino DM, Buist AS. Global burden of COPD: risk factors, prevalence, and future trends. The Lancet 2007 Sep;370(9589):765-773. [doi: 10.1016/s0140-6736(07)61380-4]

5. Braman SS. The global burden of asthma. Chest $2006 \mathrm{Jul} ; 130(1 \mathrm{Suppl}): 4 \mathrm{~S}-12 \mathrm{~S}$. [doi: 10.1378/chest.130.1 suppl.4S] [Medline: 16840363 ]

6. Hosseinzadeh H, Shnaigat M. Effectiveness of chronic obstructive pulmonary disease self-management interventions in primary care settings: a systematic review. Aust. J. Prim. Health 2019;25(3):195-204. [doi: 10.1071/py18181]

7. Raymond B, Luckett T, Johnson M, Hutchinson A, Lovell M, Phillips J. Low-intensity educational interventions supporting self-management to improve outcomes related to chronic breathlessness: a systematic review. npj Prim. Care Respir. Med 2019 Nov 29;29(1):41-49. [doi: 10.1038/s41533-019-0152-8]

8. Lorig KR, Holman HR. Self-management education: History, definition, outcomes, and mechanisms. ann. behav. med 2003 Aug;26(1):1-7. [doi: 10.1207/s15324796abm2601 01]

9. Jonkman NH, Schuurmans MJ, Groenwold RHH, Hoes AW, Trappenburg JCA. Identifying components of self-management interventions that improve health-related quality of life in chronically ill patients: Systematic review and meta-regression analysis. Patient Education and Counseling 2016 Jul;99(7):1087-1098. [doi: 10.1016/j.pec.2016.01.022] 
10. Dineen-Griffin S, Garcia-Cardenas V, Williams K, Benrimoj SI. Helping patients help themselves: A systematic review of self-management support strategies in primary health care practice. PLoS One 2019;14(8):e0220116-e0220149 [FREE Full text] [doi: 10.1371/journal.pone.0220116] [Medline: 31369582]

11. Morrison D, Mair FS, Yardley L, Kirby S, Thomas M. Living with asthma and chronic obstructive airways disease: Using technology to support self-management - An overview. Chron Respir Dis 2016 Aug 10;14(4):407-419. [doi:

$10.1177 / 1479972316660977]$

12. Eysenbach G. What is e-health? J Med Internet Res 2001 Jun 18;3(2):e20-e22. [doi: 10.2196/jmir.3.2.e20]

13. Elbert NJ, van Os-Medendorp H, van Renselaar W, Ekeland AG, Hakkaart-van RL, Raat H, et al. Effectiveness and cost-effectiveness of ehealth interventions in somatic diseases: a systematic review of systematic reviews and meta-analyses. J Med Internet Res 2014;16(4):e110-e133 [FREE Full text] [doi: 10.2196/jmir.2790] [Medline: 24739471]

14. Morrison D, Wyke S, Agur K, Cameron EJ, Docking RI, MacKenzie AM, et al. Digital Asthma Self-Management Interventions: A Systematic Review. J Med Internet Res 2014 Feb 18;16(2):e51-e71. [doi: 10.2196/jmir.2814]

15. Talboom-Kamp E, Holstege MS, Chavannes NH, Kasteleyn MJ. Effects of use of an eHealth platform e-Vita for COPD patients on disease specific quality of life domains. Respir Res 2019 Jul 10;20(1):146-155. [doi: 10.1186/s12931-019-1110-2]

16. Hallensleben C, van Luenen S, Rolink E, Ossebaard HC, Chavannes NH. eHealth for people with COPD in the Netherlands: a scoping review. COPD 2019 Jul; Volume 14:1681-1690. [doi: 10.2147/copd.s207187]

17. Hurling R, Catt M, Boni MD, Fairley BW, Hurst T, Murray P, et al. Using Internet and Mobile Phone Technology to Deliver an Automated Physical Activity Program: Randomized Controlled Trial. J Med Internet Res 2007 Apr 27;9(2):e7-31. [doi: 10.2196/jmir.9.2.e7]

18. Ariens LFM, Schussler-Raymakers FML, Frima C, Flinterman A, Hamminga E, Arents BWM, et al. Barriers and Facilitators to eHealth Use in Daily Practice: Perspectives of Patients and Professionals in Dermatology. J Med Internet Res 2017 Sep 05;19(9):e300. [doi: 10.2196/jmir.7512]

19. Kloek C, Bossen D, de Bakker DH, Veenhof C, Dekker J. Blended Interventions to Change Behavior in Patients With Chronic Somatic Disorders: Systematic Review. J Med Internet Res 2017 Dec 21;19(12):e418 [FREE Full text] [doi: 10.2196/jmir.8108] [Medline: 29269338]

20. Erbe D, Eichert HC, Riper H, Ebert DD. Blending Face-to-Face and Internet-Based Interventions for the Treatment of Mental Disorders in Adults: Systematic Review. J Med Internet Res 2017 Sep 15;19(9):e306. [doi: 10.2196/jmir.6588]

21. Rasing SPA, Stikkelbroek YAJ, Bodden DHM. Is Digital Treatment the Holy Grail? Literature Review on Computerized and Blended Treatment for Depressive Disorders in Youth. Int J Environ Res Public Health 2019 Dec 24;17(1):e306 [FREE Full text] [doi: 10.3390/ijerph17010153] [Medline: $\underline{\text { 31878249] }}$

22. Garcia-Aymerich J, Hernandez C, Alonso A, Casas A, Rodriguez-Roisin R, Anto JM, et al. Effects of an integrated care intervention on risk factors of COPD readmission. Respir Med 2007 Jul;101(7):1462-1469 [FREE Full text] [doi: 10.1016/j.rmed.2007.01.012] [Medline: 17339106]

23. Barbanel D, Eldridge S, Griffiths C. Can a self-management programme delivered by a community pharmacist improve asthma control? A randomised trial. Thorax 2003 Oct;58(10):851-854 [FREE Full text] [doi: 10.1136/thorax.58.10.851] [Medline: 14514935$]$

24. Koff PB, Jones RH, Cashman JM, Voelkel NF, Vandivier RW. Proactive integrated care improves quality of life in patients with COPD. European Respiratory Journal 2009 Jan 07;33(5):1031-1038. [doi: 10.1183/09031936.00063108]

25. van der Meer V, Bakker MJ, van den Hout WB, Rabe KF, Sterk PJ, Kievit J, et al. Internet-based self-management plus education compared with usual care in asthma: a randomized trial. Ann Intern Med 2009 Jul 21;151(2):110-120. [Medline: $\underline{19620163]}$

26. Moher D, Liberati A, Tetzlaff J, Altman DG. Preferred reporting items for systematic reviews and meta-analyses: The PRISMA statement. International Journal of Surgery 2010;8(5):336-341. [doi: 10.1016/j.ijsu.2010.02.007]

27. Frandsen TF, Nielsen MFB, Lindhardt CL, Eriksen MB. Using the full PICO model as a search tool for systematic reviews resulted in lower recall for some PICO elements. Journal of Clinical Epidemiology 2020 Nov;127:69-75. [doi: 10.1016/j.jclinepi.2020.07.005]

28. McHugh ML. Interrater reliability: the kappa statistic. Biochem Med 2012:276-282. [doi: $10.11613 / \mathrm{bm} .2012 .031]$

29. Mirza S, Clay RD, Koslow MA, Scanlon PD. COPD Guidelines: A Review of the 2018 GOLD Report. Mayo Clinic Proceedings 2018 Oct;93(10):1488-1502. [doi: 10.1016/j.mayocp.2018.05.026]

30. Chaet AV, Morshedi B, Wells KJ, Barnes LE, Valdez R. Spanish-Language Consumer Health Information Technology Interventions: A Systematic Review. J Med Internet Res 2016 Dec 10;18(8):e214 [FREE Full text] [doi: 10.2196/jmir.5794] [Medline: 27511437]

31. Gillick MR. The critical role of caregivers in achieving patient-centered care. JAMA 2013 Aug 14;310(6):575-576. [doi: 10.1001/jama.2013.7310] [Medline: 23867885]

32. Noordman J, van der Weijden T, van Dulmen S. Communication-related behavior change techniques used in face-to-face lifestyle interventions in primary care: A systematic review of the literature. Patient Education and Counseling 2012 Nov;89(2):227-244. [doi: 10.1016/j.pec.2012.07.006]

33. Sterne JAC, Savović J, Page MJ, Elbers RG, Blencowe NS, Boutron I, et al. RoB 2: a revised tool for assessing risk of bias in randomised trials. BMJ 2019 Aug 28:14898. [doi: 10.1136/bmj.14898] 
34. Guyatt GH, Oxman AD, Vist GE, Kunz R, Falck-Ytter Y, Schünemann HJ. What is "quality of evidence" and why is it important to clinicians? BMJ 2008 May 01;336(7651):995-998. [doi: 10.1136/bmj.39490.551019.be]

35. Balshem H, Helfand M, Schünemann HJ, Oxman AD, Kunz R, Brozek J, et al. GRADE guidelines: 3. Rating the quality of evidence. Journal of Clinical Epidemiology 2011 Apr;64(4):401-406. [doi: 10.1016/j.jclinepi.2010.07.015]

36. Crutzen R. Adding effect sizes to a systematic review on interventions for promoting physical activity among European teenagers. Int J Behav Nutr Phys Act 2010;7(1):29. [doi: 10.1186/1479-5868-7-29]

37. Cohen J. A power primer. Psychol Bull 1992 Jul;112(1):155-159. [Medline: 19565683]

38. Lang TA, Lang T, Secic M. How to Report Statistics in Medicine. The Nurse Practitioner 1997;22(5):198. [doi: 10.1097/00006205-199705000-00022]

39. Romeo A, Edney S, Plotnikoff R, Curtis R, Ryan J, Sanders I, et al. Can Smartphone Apps Increase Physical Activity? Systematic Review and Meta-Analysis. J Med Internet Res 2019 Mar 19;21(3):e12053. [doi: 10.2196/12053]

40. Egger M, Smith GD, Schneider M, Minder C. Bias in meta-analysis detected by a simple, graphical test. BMJ 1997 Sep 13;315(7109):629-634 [FREE Full text] [Medline: 9310563]

41. DerSimonian R, Laird N. Meta-analysis in clinical trials revisited. Contemp Clin Trials 2015 Nov;45(Pt A):139-145 [FREE Full text] [doi: 10.1016/j.cct.2015.09.002] [Medline: 26343745]

42. Higgins JPT, Green S. Cochrane Handbook for Systematic Reviews of Interventions. Cochrane. 2018. URL: https://training. cochrane.org/search/site/cochrane\%20handbook\%20systematic\%20reviews\%20interventions [accessed 2020-03-09]

43. Viechtbauer W, Cheung MW. Outlier and influence diagnostics for meta-analysis. Res Synth Methods 2010 Apr;1(2):112-125. [doi: 10.1002/jrsm.11] [Medline: 26061377]

44. Wallace BC, Schmid CH, Lau J, Trikalinos TA. Meta-Analyst: software for meta-analysis of binary, continuous and diagnostic data. BMC Med Res Methodol 2009 Dec 4;9(1):80-91. [doi: 10.1186/1471-2288-9-80]

45. Bentley CL, Mountain GA, Thompson J, Fitzsimmons DA, Lowrie K, Parker SG, et al. A pilot randomised controlled trial of a Telehealth intervention in patients with chronic obstructive pulmonary disease: challenges of clinician-led data collection. Trials 2014;15:313 [FREE Full text] [doi: 10.1186/1745-6215-15-313] [Medline: 25100550]

46. Cameron-Tucker HL, Wood-Baker R, Joseph L, Walters JA, Schüz N, Walters EH. A randomized controlled trial of telephone-mentoring with home-based walking preceding rehabilitation in COPD. Int J Chron Obstruct Pulmon Dis 2016;11:1991-2000 [FREE Full text] [doi: 10.2147/COPD.S109820] [Medline: 27601892]

47. Casas A, Troosters T, Garcia-Aymerich J, Roca J, Hernández C, Alonso A, et al. Integrated care prevents hospitalisations for exacerbations in COPD patients. Eur Respir J 2006 Jul;28(1):123-130 [FREE Full text] [doi:

10.1183/09031936.06.00063205] [Medline: 16611656 ]

48. Chau JPC, Lee DTF, Yu DSF, Chow AYM, Yu WC, Chair SY, et al. A feasibility study to investigate the acceptability and potential effectiveness of a telecare service for older people with chronic obstructive pulmonary disease. International Journal of Medical Informatics 2012 Oct;81(10):674-682. [doi: 10.1016/j.ijmedinf.2012.06.003]

49. Hæsum LKE, Ehlers LH, Hejlesen OK. The long-term effects of using telehomecare technology on functional health literacy: results from a randomized trial. Public Health 2017 Sep;150:43-50. [doi: 10.1016/j.puhe.2017.05.002] [Medline: 28623766]

50. Jehn M, Donaldson G, Kiran B, Liebers U, Mueller K, Scherer D, et al. Tele-monitoring reduces exacerbation of COPD in the context of climate change--a randomized controlled trial. Environ Health 2013;12:99 [FREE Full text] [doi: 10.1186/1476-069X-12-99] [Medline: 24261700]

51. Nguyen HQ, Donesky-Cuenco D, Wolpin S, Reinke LF, Benditt JO, Paul SM, et al. Randomized controlled trial of an internet-based versus face-to-face dyspnea self-management program for patients with chronic obstructive pulmonary disease: pilot study. J Med Internet Res 2008;10(2):e9 [FREE Full text] [doi: 10.2196/jmir.990] [Medline: 18417444]

52. Sorknaes AD, Bech M, Madsen H, Titlestad IL, Hounsgaard L, Hansen-Nord M, et al. The effect of real-time teleconsultations between hospital-based nurses and patients with severe COPD discharged after an exacerbation. J Telemed Telecare 2013 Dec;19(8):466-474. [doi: 10.1177/1357633X13512067] [Medline: 24227799]

53. Stamenova V, Liang K, Yang R, Engel K, van Lieshout F, Lalingo E. Technology-Enabled Self-Management of Chronic Obstructive Pulmonary Disease With or Without Asynchronous Remote Monitoring: Randomized Controlled Trial. J Med Internet Res, 2020 2020;22(7):e18598. [doi: 10.2196/preprints. 18598]

54. Wang L, He L, Tao Y, Sun L, Zheng H, Zheng Y, et al. Evaluating a Web-Based Coaching Program Using Electronic Health Records for Patients With Chronic Obstructive Pulmonary Disease in China: Randomized Controlled Trial. J Med Internet Res 2017 Jul 21;19(7):e264 [FREE Full text] [doi: 10.2196/jmir.6743] [Medline: 28733270]

55. Wang LH, Guo YM, Wang ML, Zhao Y. A mobile health application to support self-management in patients with chronic obstructive pulmonary disease: a randomised controlled trial. Clin Rehabil 2020 Sep 09;35(1):90-101. [doi: $10.1177 / 0269215520946931]$

56. Wei L, Yang XY, Li J, Liu LH, Luo HY, Zheng ZG. Effect of pharmaceutical care on medication adherence and hospital admission in patients with chronic obstructive pulmonary disease (COPD): a randomized controlled study. J Thorac Dis 2014;6(6):656-662. 
57. Xin CW, Xia ZN, Jiang C, Lin MM, Li GH. The impact of pharmacist-managed clinic on medication adherence and health-related quality of life in patients with COPD: a randomized controlled study. PPA 2016 Jul;Volume 10:1197-1203. [doi: 10.2147/ppa.s110167]

58. Cao Y, Lin SH, Zhu D, Xu F, Chen ZH, Shen HH, et al. WeChat Public Account Use Improves Clinical Control of Cough-Variant Asthma: A Randomized Controlled Trial. Med Sci Monit 2018 Mar 14;24:1524-1532 [FREE Full text] [doi: 10.12659/msm.907284] [Medline: 29536984]

59. Kohler B, Kellerer C, Schultz K, Wittmann M, Atmann O, Linde K. An Internet-Based Asthma Self-Management Program Increases Knowledge About Asthma Results of a Randomized Controlled Trial. Dtsch Arztebl Int 2020;117(5):64-71. [doi: 10.3238/arztebl.2020.0064]

60. Ostojic V, Cvoriscec B, Ostojic SB, Reznikoff D, Stipic-Markovic A, Tudjman Z. Improving asthma control through telemedicine: a study of short-message service. Telemed J E Health 2005 Feb;11(1):28-35. [doi: 10.1089/tmj.2005.11.28] [Medline: 15785218]

61. Türk Y, Theel W, van Huisstede A, van de Geijn GM, Birnie E, Hiemstra PS, et al. Short-term and long-term effect of a high-intensity pulmonary rehabilitation programme in obese patients with asthma: a randomised controlled trial. Eur Respir J 2020 Jul;56(1):1901820. [doi: 10.1183/13993003.01820-2019] [Medline: 32299852]

62. van Gaalen JL, Beerthuizen T, van der Meer MV, van Reisen P, Redelijkheid GW, Snoeck-Stroband JB, et al. Long-term outcomes of internet-based self-management support in adults with asthma: randomized controlled trial. J Med Internet Res 2013;15(9):e188 [FREE Full text] [doi: 10.2196/jmir.2640] [Medline: 24028826]

63. Sundberg R, Tunsäter A, Palmqvist M, Ellbjär S, Löwhagen O, Torén K. A randomized controlled study of a computerized limited education program among young adults with asthma. Respir Med 2005 Mar;99(3):321-328 [FREE Full text] [doi: 10.1016/j.rmed.2004.08.006] [Medline: $\underline{15733508]}$

64. Peytremann-Bridevaux I, Staeger P, Bridevaux PO, Ghali WA, Burnand B. Effectiveness of Chronic Obstructive Pulmonary Disease-Management Programs: Systematic Review and Meta-Analysis. The American Journal of Medicine 2008 May;121(5):433-443.e4. [doi: 10.1016/j.amjmed.2008.02.009]

65. Lundell S, Holmner A, Rehn B, Nyberg A, Wadell K. Telehealthcare in COPD: a systematic review and meta-analysis on physical outcomes and dyspnea. Respir Med 2015 Jan;109(1):11-26. [doi: 10.1016/j.rmed.2014.10.008] [Medline: 25464906]

66. Cannon D, Buys N, Sriram KB, Sharma S, Morris N, Sun J. The effects of chronic obstructive pulmonary disease self-management interventions on improvement of quality of life in COPD patients: A meta-analysis. Respir Med 2016 Dec;121:81-90 [FREE Full text] [doi: 10.1016/j.rmed.2016.11.005] [Medline: 27888996]

67. Long H, Howells K, Peters S, Blakemore A. Does health coaching improve health-related quality of life and reduce hospital admissions in people with chronic obstructive pulmonary disease? A systematic review and meta-analysis. Br J Health Psychol 2019 Sep;24(3):515-546 [FREE Full text] [doi: 10.1111/bjhp.12366] [Medline: $\underline{\text { 31033121] }}$

68. Ridwan ES, Hadi H, Wu YL, Tsai PS. Effects of Transitional Care on Hospital Readmission and Mortality Rate in Subjects With COPD: A Systematic Review and Meta-Analysis. Respir Care 2019 Aug 29;64(9):1146-1156. [doi: 10.4187/respcare.06959]

69. Simonelli C, Vitacca M, Vignoni M, Ambrosino N, Paneroni M. Effectiveness of manual therapy in COPD: A systematic review of randomised controlled trials. Pulmonology 2019 Jul;25(4):236-247. [doi: 10.1016/j.pulmoe.2018.12.008]

70. Sul AR, Lyu DH, Park DA. Effectiveness of telemonitoring versus usual care for chronic obstructive pulmonary disease: A systematic review and meta-analysis. J Telemed Telecare 2018 Dec 12;26(4):189-199. [doi: 10.1177/1357633x18811757]

71. Imamura S, Inagaki T, Terada J, Nagashima K, Katsura H, Tatsumi K. Long-term efficacy of pulmonary rehabilitation with home-based or low frequent maintenance programs in patients with chronic obstructive pulmonary disease: a meta-analysis. Ann Palliat Med 2020 Sep;9(5):2606-2615. [doi: 10.21037/apm-19-581]

72. Murphie P, Little S, McKinstry B, Pinnock H. Remote consulting with telemonitoring of continuous positive airway pressure usage data for the routine review of people with obstructive sleep apnoea hypopnoea syndrome: A systematic review. $\mathbf{J}$ Telemed Telecare 2019 Jan;25(1):17-25. [doi: 10.1177/1357633X17735618] [Medline: 28990455]

73. Mubarak N, Hatah E, Khan TM, Zin CS. A systematic review and meta-analysis of the impact of collaborative practice between community pharmacist and general practitioner on asthma management. J Asthma Allergy 2019;12:109-153 [FREE Full text] [doi: 10.2147/JAA.S202183] [Medline: $\underline{\text { 31213852] }}$

74. Chongmelaxme B, Lee S, Dhippayom T, Saokaew S, Chaiyakunapruk N, Dilokthornsakul P. The Effects of Telemedicine on Asthma Control and Patients' Quality of Life in Adults: A Systematic Review and Meta-analysis. The Journal of Allergy and Clinical Immunology: In Practice 2019 Jan;7(1):199-216.e11. [doi: 10.1016/j.jaip.2018.07.015]

75. Baishnab E, Karner C. Primary care based clinics for asthma. Cochrane Database Syst Rev 2012. [doi: 10.1002/14651858.cd003533.pub2]

76. Hansen ESH, Pitzner-Fabricius A, Toennesen LL, Rasmusen HK, Hostrup M, Hellsten Y, et al. Effect of aerobic exercise training on asthma in adults: a systematic review and meta-analysis. Eur Respir J 2020 Apr 29;56(1):2000146. [doi: 10.1183/13993003.00146-2020]

77. Guyatt GH, Oxman AD, Kunz R, Woodcock J, Brozek J, Helfand M, et al. GRADE guidelines: 7. Rating the quality of evidence_-inconsistency. Journal of Clinical Epidemiology 2011 Dec;64(12):1294-1302. [doi: 10.1016/j.jclinepi.2011.03.017] 


\title{
Abbreviations
}

BCT: behavior change technique

CAT: chronic obstructive pulmonary disease assessment test

CG: control group

CONSORT: Consolidated Standards of Reporting Trials

COPD: chronic obstructive pulmonary disease

CRQ: chronic respiratory questionnaire

DALY: disability-adjusted life year

FEV1: forced expiratory volume in $1 \mathrm{~s}$

FVC: forced vital capacity

GOLD: Global Initiative for Chronic Obstructive Lung Disease

GRADE: Grading of Recommendations, Assessment, Development, and Evaluation

IG: intervention group

PC: primary care

PRISMA: Preferred Reporting Items for Systematic Reviews and Meta-Analyses

QALY: quality-adjusted life year

QoL: quality of life

RCT: randomized controlled trial

ROB: risk of bias

RR: relative ratio

SC: secondary care

SGRQ: Saint-George's Respiratory Questionnaire

SMD: standardized mean difference

UC: usual care

\author{
Edited by G Eysenbach; submitted 26.09.20; peer-reviewed by $T$ Ndabu, $Y$ Wang, D Erbe, R Bajpai, E Drokow; comments to author \\ 26.11.20; revised version received 17.01.21; accepted 18.01.21; published 31.03.21 \\ Please cite as: \\ Song X, Hallensleben C, Zhang W, Jiang Z, Shen H, Gobbens RJJ, Kleij RMJJVD, Chavannes NH, Versluis A \\ Blended Self-Management Interventions to Reduce Disease Burden in Patients With Chronic Obstructive Pulmonary Disease and \\ Asthma: Systematic Review and Meta-analysis \\ J Med Internet Res 2021;23(3):e24602 \\ URL: https://www.jmir.org/2021/3/e24602 \\ doi: $10.2196 / 24602$ \\ PMID: $\underline{3788700}$
}

(CXiaoyue Song, Cynthia Hallensleben, Weihong Zhang, Zongliang Jiang, Hongxia Shen, Robbert J J Gobbens, Rianne M J J Van Der Kleij, Niels H Chavannes, Anke Versluis. Originally published in the Journal of Medical Internet Research (http://www.jmir.org), 31.03.2021. This is an open-access article distributed under the terms of the Creative Commons Attribution License (https://creativecommons.org/licenses/by/4.0/), which permits unrestricted use, distribution, and reproduction in any medium, provided the original work, first published in the Journal of Medical Internet Research, is properly cited. The complete bibliographic information, a link to the original publication on http://www.jmir.org/, as well as this copyright and license information must be included. 